Aus der Klinik für Gastroenterologie und Endokrinologie (kommissarische Leitung Prof. Dr. med. T. Sauerbruch) im Zentrum Innere Medizin der Medizinischen Fakultät der Universität Göttingen

\title{
The role of leptin and insulin signaling in the hypothalamic control of liver metabolism
}

\author{
Inaugural-Dissertation \\ zur Erlangung des Doktorgrades \\ der Medizinischen Fakultät \\ der Georg-August-Universität zu Göttingen
}

vorgelegt von

Martin Faßhauer

aus Göttingen

Göttingen 2013 
Dekan:

I. Berichterstatter:

II. Berichterstatter/in:

III. Berichterstatter/in:

Tag der mündlichen Prüfung: 28. Oktober 2013
Prof. Dr. rer. nat. H.K. Kroemer

Prof Dr. med. D. Raddatz

Prof. Dr. rer. nat. B. Schwappach

Prof. Dr. med. dent. Mausberg 


\section{Table of contents}

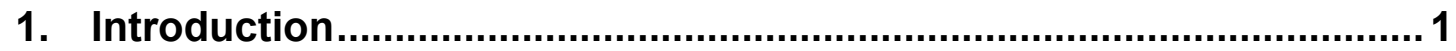

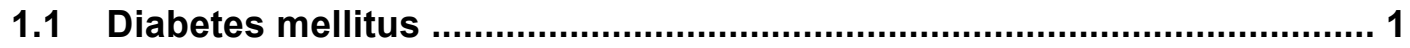

1.1.1 Classification of diabetes mellitus ...................................................... 2

1.2 Hypothalamic leptin and insulin signaling ........................................... 3

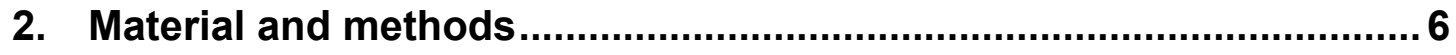

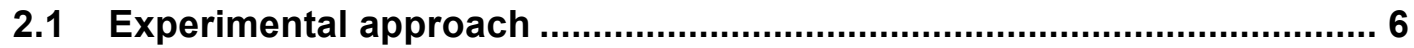

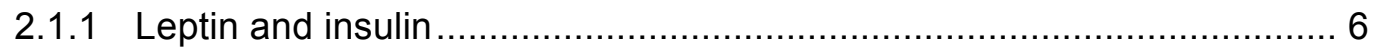

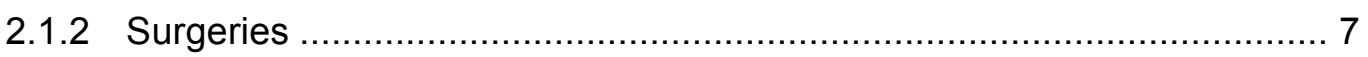

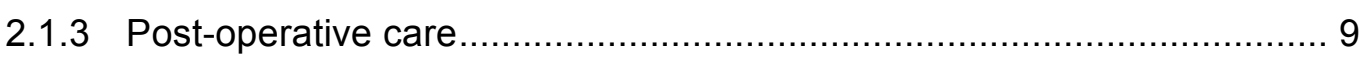

2.1.4 Euglycemic pancreatic clamp protocol .......................................... 10

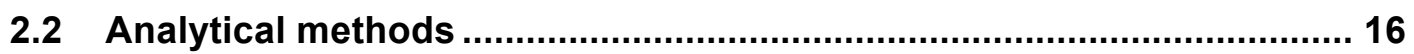

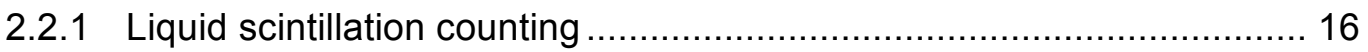

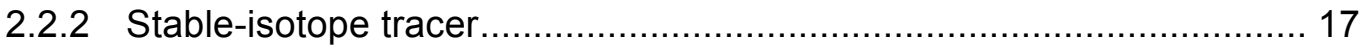

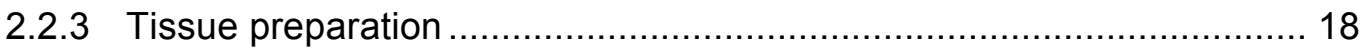

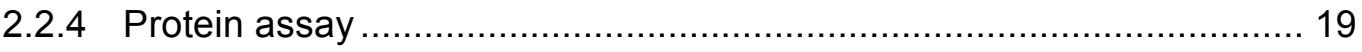

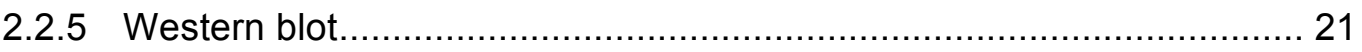

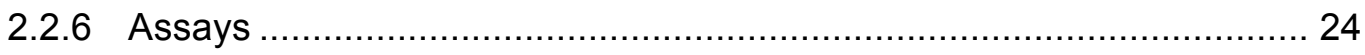

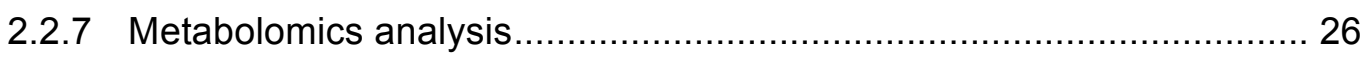

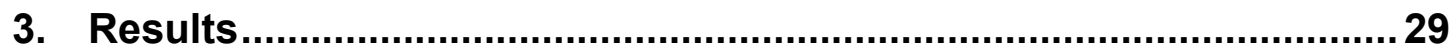

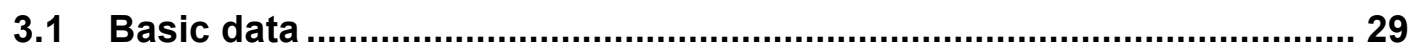

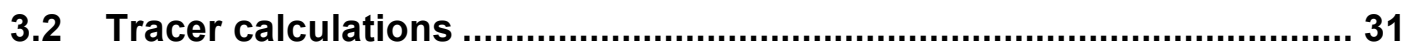

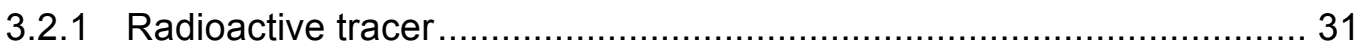

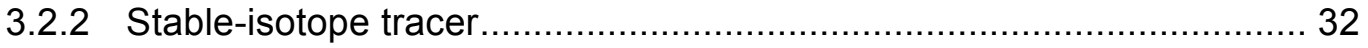

3.3 Triglyceride, free glycerol and NEFA plasma levels............................ 33

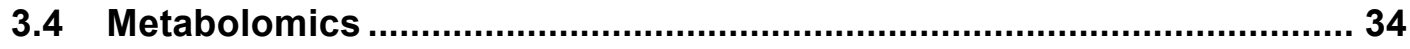

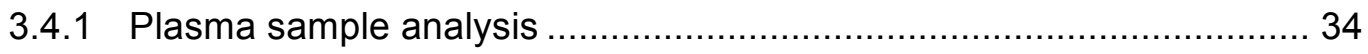

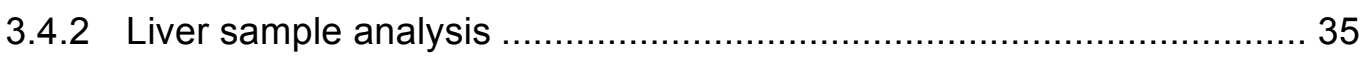

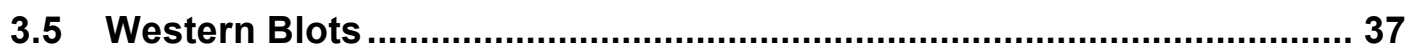

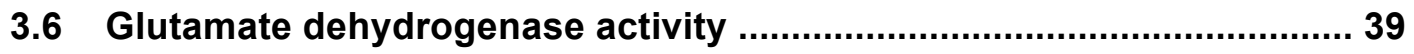

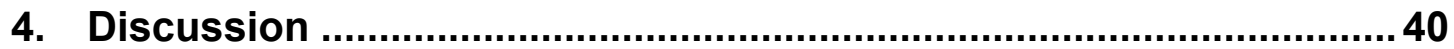

4.1 $\mathrm{MBH}$ leptin and insulin ameliorate insulin resistance, suppress long chain fatty acid oxidation in the liver and lead to a decrease in circulating BCAAs. 
Central leptin and insulin suppress long chain fatty acid $\beta$-oxidation in the liver and promote switch from lipid to carbohydrate and amino acid utilization. ....... 40

$\mathrm{MBH}$ insulin alters hepatic protein synthesis............................................. 42

MBH leptin and MBH insulin's effect on fatty acid synthesis in liver tissue ....... 43

$\mathrm{MBH}$ leptin suppresses hepatic glucose production

Conclusion, Implications for the pathogenesis of diabetes mellitus and possible treatment options

4.2 Limitations. 48

Group size and the use of an animal model. 48

5. Summary 49

6. References 51 


\section{Index of abbreviations}

\begin{tabular}{|c|c|}
\hline AA & amino acid \\
\hline$A B$ & antibody \\
\hline$A C$ & acylcarnitine \\
\hline $\mathrm{ACC}$ & acetyl-CoA carboxylase \\
\hline aCSF & artificial cerebro spinal fluid \\
\hline ADA & American Diabetes Association \\
\hline $\mathrm{AgRP}$ & agouti-related peptide \\
\hline Ala & alanine \\
\hline AMP & adenosine monophosphate \\
\hline AMPK $\alpha$ & AMP-activated protein kinase $\alpha$ subunit \\
\hline Arg & arginine \\
\hline As $\mathrm{x}$ & asparagine + aspartate \\
\hline ATP & adenosine-5'-triphosphate \\
\hline BCA & bicinchoninic acid \\
\hline BCAA & branched-chain amino acid \\
\hline BSA & bovine serum albumin \\
\hline BW & bodyweight \\
\hline Cit & citrulline \\
\hline CNS & central nervous system \\
\hline CoA & coenzyme A \\
\hline CPT-1 & carnitine palmitoyltransferase 1 \\
\hline $\mathrm{dH} 2 \mathrm{O}$ & deionized water \\
\hline DM & diabetes mellitus \\
\hline DM1 & diabetes mellitus type 1 \\
\hline DM2 & diabetes mellitus type 2 \\
\hline EDTA & ethylenediaminetetraacetic acid \\
\hline eGP & endogenous glucose production \\
\hline EGTA & ethylene glycol tetraacetic acid \\
\hline ENR & isotopic enrichment fraction \\
\hline FA & final absorbance \\
\hline FAS & fatty acid synthase \\
\hline
\end{tabular}


FFA

GAPDH

GC/MS

GIR

GLDH

GIx

Gly

GP

G6Pase

hGP

His

HPLC

IA

ICV

IDDM

IFG

$\lg G$

IGT

Ile

inf

ins

IP

IV

lep

Leu

m

$\mathrm{MBH}$

Met

MOPS

MS

$\mathrm{MSH}$

MS-MS free fatty acid

Glyceraldehyde 3-phosphate dehydrogenase

gas chromatography-mass spectrometry

glucose infusion rate

glutamate-dehydrogenase

glutamine + glutamate

glycine

glucose production

glucose 6 phosphatase

hepatic glucose production

histidine

high-performance liquid chromatography

initial absorbance

intracerebroventricular

insulin-dependent diabetes mellitus

impaired fasting glucose

immunoglobulin G

impaired glucose tolerance

isoleucine

infusion

insulin

intraperitoneal

intravenous

leptin

leucine

mass

mediobasal hypothalamus

methionine

3-(N-morpholino)propanesulfonic acid

mass spectrometer or mass spectrometry

melanocyte-stimulating hormone

tandem-mass spectrometry 
$\mathrm{NADH}$

NEFA

NIDDM

NPY

OA

Orn

pAMPK

PEPCK

Phe

pl

POMC

Pro

R

$\mathrm{Ra}$

$\mathrm{Rd}$

SDS

Ser

SEM

STAT3

TBS

TBS-T

TCA

TG

Thr

Tyr

Val

$\mathrm{VMH}$

WAT

WHO

WT

z reduced form of Nicotinamide adenine dinucleotide non-esterified fatty acid

non-insulin dependent diabetes mellitus

neuropeptide $Y$

organic acid

ornithine

Thr 172 phosphorylated AMPK $\alpha$

Phosphoenolpyruvate carboxykinase

phenylalanine

plasma

proopiomelanocortin

proline

infusion Rate

rate of appearance

rate of disappearance

Sodium dodecyl sulfate

serine

standard error of the mean

signal transducer and activator of transcription 3

tris-buffered saline

tris-buffered saline including Tween $\AA$

tricarboxylic acid

triglycerides

threonine

tyrosine

valine

ventromedial hypothalamus

white adipose tissue

World Health Organization

wildtype

charge number 


\section{Introduction}

The past decades have seen a dramatic increase in obesity and type 2 diabetes mellitus (DM) in all age-groups (Amiel et al. 1986, Ginter and Simko 2012, Pinhas-Hamiel and Zeitler 2005), and the metabolic pathways responsible for its development, are the target of ongoing research. The brain plays a central role in whole body energy homeostasis, integrating neuronal and humoral signals from the periphery. Evaluating the pathways involved will therefore be the basis to further our understanding of obesity and diabetes. The present work tries to further assess the role of the brain, in particular the role of the hypothalamus, in regulating glucose and lipid metabolism, by using targeted metabolomic profiling. First, I will describe the basic principles of DM and its epidemiological importance, before explaining the rationale for conducting these studies.

\subsection{Diabetes mellitus}

Characterized by chronic hyperglycemia, DM is a disorder of either impaired insulin production or sensitivity and therefore affects whole body metabolism. This not only leads to secondary damages, such as microangiopathy or peripheral neuropathy, but also holds the danger of diabetic ketoacidosis and coma (Berry et al. 2012, de Boer et al. 2011, Felig 1974, Holman et al. 2008, Mauer et al. 2009, Patel et al. 2008, Tesfaye et al. 2005).

According to the World Health Organization (WHO), DM is diagnosed if the patient shows classical symptoms, like polyuria, polydipsia, weight loss, fatigue, and his fasting plasma glucose concentration is $\geq 7 \mathrm{mmol} / \mathrm{L}$ (126 $\mathrm{mg} / \mathrm{dL}$ ) or $\geq 11.1 \mathrm{mmol} / \mathrm{L}$ ( $200 \mathrm{mg} / \mathrm{dL}$ ), 2 hours after a $75 \mathrm{~g}$ glucose drink. In addition to impairing fasting glucose (IFG), intermediate states impair glucose tolerance (IGT) and frequently lead to diabetes mellitus type 2 (DM2). IFG is defined by the American Diabetes Association (ADA) as fasting plasma glucose $\geq 5.6 \mathrm{mmol} / \mathrm{L}(100 \mathrm{mg} / \mathrm{dL})$ and $<7 \mathrm{mmol} / \mathrm{L}(126 \mathrm{mg} / \mathrm{dL})$, whereas the 
intermediate levels of IGT require plasma glucose levels to be $\geq 7.8 \mathrm{mmol} / \mathrm{L}$ $(140 \mathrm{mg} / \mathrm{dL})$ and $<11.1 \mathrm{mmol} / \mathrm{L}(200 \mathrm{mg} / \mathrm{dL}) 2$ hours after a $75 \mathrm{~g}$ glucose drink.

\subsubsection{Classification of diabetes mellitus}

\section{Type 1 diabetes}

Diabetes mellitus type 1 (DM1) is characterized by absolute insulin deficiency usually due to autoimmune destruction of the beta cells of the pancreas. This form was formerly known as insulin-dependent diabetes mellitus (IDDM) in comparison to non-insulin dependent diabetes mellitus (NIDDM). DM1 mostly develops in children and adolescents that require insulin injections for survival and patients are more susceptible to ketoacidosis or diabetic coma.

\section{Type 2 diabetes}

This type of diabetes strongly correlates with obesity, insufficient physical activity, unhealthy diet and includes $90 \%$ of the patients with DM. It usually develops in adults showing few or no symptoms for years, due to compensatory insulin production by the beta-islet cells. Insulin resistance as well as impaired glucose tolerance follows, resulting in increased fasting plasma glucose, which results in development of an intermediate stage. Generally, there is a good chance of resolving DM2 in the intermediate stage, if the patient is willing to adhere to a healthier lifestyle and substantial weight loss.

\section{Prevalence}

Using the above mentioned guidelines, the age-standardized prevalence of DM was about $9.5 \%$ in 2008, i.e. about 346 million people worldwide met the criteria for DM (Danaei et al. 2011). In Germany, the population that were being treated for DM rose from 5.9\% in 1998 to 8.9\% in 2007 (Rathmann et al. 2009). This increase was mainly caused by the early onset of obesity in adolescents and children as well as the overall increase in life expectancy. Nonetheless DM remains as a global epidemic and public awareness should be increased. The consumption of high sugar, high fat food and a sedentary life style are the major causes for this epidemic. 


\subsection{Hypothalamic leptin and insulin signaling}

Hyperinsulinemia and hyperleptinemia are hallmarks of insulin resistance and obesity, respectively. Hepatic insulin resistance develops early in DM2 and is at least in part regulated by brain signaling (Ono et al. 2008). While insulin has numerous functions as a systemic hormone, leptin's role in energy metabolism was first discovered through its actions in the central nervous system and its ability to reduce food intake in a rodent model (Campfield et al. 1995, Halaas et al. 1995). The hypothalamus plays an integral role in nutrient sensing and the regulation of glucose homeostasis as well as obesity (Jung and Kim 2013, Lam et al. 2010, Lam et al. 2005, Pocai et al. 2005c, Pocai et al. 2006, Toda et al. 2013). In rats for example, hypothalamic sensing of intact free fatty acid (FFA) prevents an exacerbated increase in hepatic glucose production due to elevated plasma FFA levels (Lam et al. 2005).

Since energy homeostasis is not only determined by caloric intake, but also through regulation of nutrient partitioning, we probed the role of leptin and insulin signaling in hypothalamic control of whole body glucose and lipid metabolism (Schwartz et al. 2000, Schwartz and Porte 2005). Within the hypothalamus, several neuronal populations in the mediobasal hypothalamus $(\mathrm{MBH})$, regulate glucose metabolism (Buettner and Camacho 2008, Obici et al. 2002, Wu et al. 2009) and express insulin as well as leptin receptors (Baskin et al. 1999, Pansky and Hatfield 1978).

Produced by adipocytes, leptin has a high impact on metabolism as a hormone acting through the central nervous system (CNS) (Campfield et al. 1995, Cohen et al. 2001, Halaas et al. 1995, Montague et al. 1997, Pelleymounter et al. 1995, Weigle et al. 1995, Zhang et al. 2010). Part of its regulatory functions in glucose metabolism can be explained through an increase in hypothalamic insulin sensitivity (Koch et al. 2010), while intact signal transducer and activator of transcription 3 (STAT3) signaling is crucial for its ability to reduce food intake and maintenance of glucose homeostasis (Buettner et al. 2006). Administered into the MBH it is able to suppress de novo lipogenesis as well as free fatty acid (FFA) uptake in white adipose tissue (WAT) (Buettner et al. 2008) through increase in sympathetic activity, 
independently from STAT3 signaling. Acutely administered into the third ventricle of Sprague-Dawley (SD) rats, leptin leads to a decrease in hepatic glycogenolysis and an increase in gluconeogenesis when circulating insulin is kept constant using pancreatic clamps. The increase in gluconeogenesis is due to the effect of melanocyte-stimulating hormone (MSH) signaling in the brain, as the effect could be blunted by co-administration of a $\mathrm{MSH}$-inhibitor (Gutierrez-Juarez et al. 2004). While this model emphasized the role of leptin signaling in the whole brain, we have tried to focus only on hypothalamic signaling by direct administration of leptin into the $\mathrm{MBH}$ under pancreatic clamp conditions.

Centrally administered insulin on the other hand reduces food intake via hypothalamic signaling (Air et al. 2002, Chavez et al. 1995, Woods et al. 1979) and plays an important role in whole body glucose and lipid metabolism (Bruning et al. 2000, Lindtner et al. 2013, Obici et al. 2002, Scherer et al. 2012), as it suppresses hepatic glucose production (Pocai et al. 2005a) and leads to an increase of de novo lipogenesis in WAT.

Since both, insulin and leptin, have numerous effects on energy metabolism through brain signaling, we established an unbiased, non-hypothesis-driven, approach to analyse metabolic pathways using different isotope-tracers and mass spectrometry for targeted metabolomics. These techniques helped us in building hypotheses and in further studying metabolic pathways possibly involved in the pathogenesis of DM. To eliminate fluctuations in plasma glucose and hormone levels, which may be caused due to the effect of central leptin and insulin on the endocrine pancreas, we combined stereotaxic infusions in the $\mathrm{MBH}$ with euglycemic clamp protocols. This protocol further allowed us to determine metabolite fluxes through tracer-dilution studies. Either radioactive or non-radioactive isotope-tracer dilution techniques using glucose, L-leucine and glycerol served the purpose of determining endogenous glucose production/uptake, proteolysis and lipolysis in vivo during the pancreatic clamps.

A metabolomic approach, such as acylcarnitine measurement, enabled us to measure the metabolite flux through mitochondrial membranes and point out 
the origin of the signal based on the acylcarnitines chain length (Koves et al. 2008). Via measurement of other metabolites such as amino acids, it was possible to investigate earlier observations that had implied an association between DM and amino acid metabolism (Felig et al. 1969, Krebs et al. 2002, Lu et al. 2013b, Michaliszyn et al. 2012).

Since mass spectrometry can analyse levels of metabolites this approach was used in particular, to study pathways directly involved in nutrient partitioning, metabolite breakdown and synthesis.

The TCA cycle plays an important role in energy metabolism (Koubaa et al. 2013), having versatile sources involving glucose, triglycerides and protein. In addition to plasma samples, liver tissue was suitable to analyze biochemical pathways, as it is a major organ of metabolism involved in breakdown, distribution and genesis of different kinds of energy metabolites. This study therefore focuses on the mechanisms by which central leptin and insulin affect hepatic downstream pathways including fatty acid synthesis, $\beta$ oxidation, glycolysis, gluconeogenesis or the citric acid (TCA) cycle. 


\section{Material and methods}

\subsection{Experimental approach}

\subsubsection{Administration of hypthalamic Leptin and insulin and measurement of systemic metabolites}

Our studies were performed in 10 - 12 week old male Sprague Dawley rats. Five groups of animals ( $n=4-7$ for each time point and experiment) were studied. One week prior to the experiments the rats had stereotaxic cannulae implanted into their $\mathrm{MBH}$ and after about 5 days of recovery, they received an intra-venous and an intra-arterial catheter through a second surgery.

During the course of the experiment we sampled 100-500 $\mu \mathrm{L}$ blood every 15 minutes to determine plasma glucose levels. To control glucose concentrations, a variable infusion of $25 \%$ glucose solution was used to clamp the plasma concentration at basal $(\sim 100-130 \mathrm{ml} / \mathrm{dl})$ levels. Animals that received $\mathrm{MBH}$ insulin (Humulin $\mathrm{R}$, Lilly), leptin (Sigma-Aldrich, St. Louis, $\mathrm{MO}$ ) or suitable vehicle (aCSF, Harvard Apparatus, Holliston, MA) received primed-continuous intravenous (IV) infusions of non-radioactive [ $\left.{ }^{2} \mathrm{H}-5\right]-$ Glycerol (1 $\left.\mu \mathrm{mol} / \mathrm{min}^{*} \mathrm{~kg}-1\right)$, (Isotec Miamisburg, OH) and L-Leucine [5,5,5-D3] (1 $\left.\mathrm{mmol}^{*} \mathrm{~min}-1^{*} \mathrm{~kg}-1\right)$ (Cambridge Isotope Laboratories, Inc., Andover, MA) from time $\mathrm{t}=-120 \mathrm{~min}$ followed by a $4 \mathrm{hr}$ pancreatic euglycemic clamp which started at $\mathrm{t}=0$. In addition to non-radioactive tracer, we repeated $\mathrm{MBH}$ aCSF and $\mathrm{MBH}$ leptin clamps using radioactive tracers to re-evaluate the impact of $\mathrm{MBH}$ leptin signaling on glucose metabolism. A prime-continuous infusion consisting of a $20 \mu \mathrm{Ci}$ bolus followed by a $0.5 \mu \mathrm{Ci} / \mathrm{min}$ infusion of $\left[3-{ }^{3} \mathrm{H}\right]-$ glucose (Perkinelmer, Waltham, MA) and [ $\left.{ }^{2} \mathrm{H}-5\right]-$ Glycerol $(40 \mu \mathrm{mol} / \mathrm{kg}$ bolus, followed by a $1 \mu \mathrm{mol} / \mathrm{min}^{*} \mathrm{~kg}-1$ infusion, Isotec Miamisburg, $\mathrm{OH}$ ) was initiated and maintained throughout the study. Non-radioactive tracers were used to avoid possible malfunctioning of the mass-spectrometer used for metabolomic analysis, which could arise from interactions with radioactive substances. Proposed study protocols and dosages were based on previously published protocols (Buettner et al. 2008, Carvalheira et al. 2003, Roman et al. 2005): 
A) 6 hours $\mathrm{MBH}$ vehicle $(0.18 \mu \mathrm{l} / \mathrm{hr}$ per side $)+4$ hours euglycemic (100 $130 \mathrm{mg} / \mathrm{dl}$ ) pancreatic/insulin (1 mU/kg.min) clamp.

B) 6 hours $\mathrm{MBH}$ leptin $(0.18 \mu \mathrm{l} / \mathrm{hr}$ per side $)(200 \mathrm{ng} / \mathrm{side})+4$ hours euglycemic (100 - $130 \mathrm{mg} / \mathrm{dl})$ pancreatic/insulin (1 mU/kg.min) clamp.

C) 6 hours $\mathrm{MBH}$ insulin $(0.18 \mu \mathrm{l} / \mathrm{hr}$ per side $)(2 \mu \mathrm{U} / \mathrm{side})+4$ hours euglycemic (100 - $130 \mathrm{mg} / \mathrm{dl})$ pancreatic/insulin (1 mU/kg.min) clamp.

All animal protocols were approved by the The Institutional Animal Care and Use Committee of The Mount Sinai School of Medicine (Protocol number: LA09-00174). Experiments were performed in male SD rats (Charles River Breeding Laboratories, Wilmington, MA). Rats were on a standard rodent diet (Rodent Diet 5001, LabDiet, St. Louis, MO) and housed individually in separate cages in a temperature- and light- controlled facility $\left(21^{\circ} \mathrm{C}, 12\right.$-hour light-dark cycle). At the end of the experiment the rats were anesthetized with ketamine and then decapitated. We injected food dye into the cannulae to confirm their correct placement. Immediately after death of the rats the organs were promptly harvested, clamp frozen in liquid nitrogen (T.W. Smith, Brooklyn, NY) and stored until further analysis at $-80^{\circ} \mathrm{C}$. In order to analyze the samples using metabolomics (realized by the Stedman Labarotories, Duke University, NC) we used non-radioactive isotope tracers.

\subsubsection{Surgeries}

\section{Anesthesia}

Rats were injected with approximately $300 \mu \mathrm{L}$ intraperitoneal (IP) $(100 \mu \mathrm{L}$ $1100 \mathrm{~g}$ bodyweight) of ketamine + xylazine mix $(200 \mu \mathrm{L}$ ketamine $\mathrm{HCL}$ $(100 \mathrm{mg} / \mathrm{ml})+100 \mu \mathrm{L}$ Xylazine $(20 \mathrm{mg} / \mathrm{ml})$ (obtained from and controlled by the Center for Comparative Medicine and Surgery of Mount Sinai School Of Medicine (CCMS)) with a hypodermic 26G Needle and $1 \mathrm{~mL}$ Syringe (both BD, Franklin Lakes, $\mathrm{NJ}$ ). To ensure surgical anesthesia, respiratory rate was monitored continuously and loss of withdrawal reflex was checked initially by pinching the rat's foot, and throughout the surgery if in doubt of surgical 
anesthesia (Alves et al. 2010). In case of initially inadequate anesthesia, rats were injected IP with $1 / 3$ of the initial dose into the contralateral side of the abdomen, while loss of sedation or analgesia during surgery was usually counteracted by isoflurane inhalation $(2-3 \%, 100-200 \mathrm{~mL} / \mathrm{min}$ gas flow), using a high precision vaporizer system (V3000PK, Parkland Scientific, Coral Springs, FL). When fully anesthetized, the surgical area was shaved using an animal clipper (Sunbeam-Oster Co., Inc., Fort Lauderdale, FL) and Puralube Eye-Lubricant was evenly spread in the inferior eyelid to prevent corneal defects (Dechra Veterinary Products, Overland Park, KS). The surgical area was then disinfected three times using betadine scrub once followed by alcohol swabs twice.

\section{Implantation of Double cannulae into the MBH}

Using a sterile surgical blade an incision was made on the scalp to expose the skull. The rat was then fitted in a stereotactic frame (Stoelting Co., Wood Dale, IL). Measuring the depth of the bregma and lambda we allowed a difference range of $0.01 \mathrm{~mm}$. 3 small, $1 \mathrm{~mm}$ diameter holes were drilled using a sterile hand held $1 \mathrm{~mm}$ long drill bit in a triangle pattern spanning the bregmoidal suture of the dorsal skull surface. $1 \mathrm{~mm}$ diameter sterile stainless steel skull screws were implanted in each hole. Stereotactic coordinates were selected according to the Paxinos Rat Brain Atlas (Paxinos and Watson 1998). We then implanted a 26-gauge dual guide cannula system for $\mathrm{MBH}$ (PlasticsOne, Roanoke, VA). The coordinates used for the $\mathrm{MBH}$ were $3.3 \mathrm{~mm}$ posterior from the bregma, $0.4 \mathrm{~mm}$ bilateral from midline and $9.6 \mathrm{~mm}$ below the surface of the skull. Guide cannulas were blocked using dummy cannulas (PlasticsOne, Roanoke, VA) until the day of the experiment. The implant was secured to the skull with Loctite 454 Instant Adhesive and Caulk Grip dental cement, the skin was closed over the implant using wound clips. If any bleeding occurred throughout this procedure it was controlled with sterile gauze or chemically cauterized using silver nitrate applicators. 


\section{Implantation of double catheters}

A longitudinal cut of approximately $2 \mathrm{~cm}$ was made from the right jugular vein towards the contralateral jugular vein using fine scissors (all surgical instruments were purchased from Fine Science Tools (USA), Inc., Foster City, CA). The jugular vein was located, dissected, adherent tissue removed using forceps (Moria Iris Forceps, serrated, curved) and ligated off the cranial end of the jugular vein using 6/0 braided silk suture (Ethicon, Somerville, NJ). Before cutting the suture the ends of the vein were used to cut a small hole at a tangential angle. After successfully placing the jugular catheter (Polyurethane Catheter, custom made by Instech Laboratories, Inc., Plymouth Meeting, PA) prefilled with heparinized-saline $(200 \mathrm{U} / \mathrm{mL})$, placement was ensured through the ease of pulling back blood into the catheter tip. Having ensured correct placement, the vein containing the catheter was sutured and flushed with approximately $0.1 \mathrm{ml}$ heparinized-saline and the catheter was blocked with a stainless steel catheter plug (Instech Laboratories). The carotid artery was then located and dissected in the same manner, using a bullfrog clamp before cutting the artery to avoid blood loss. After both catheters were placed, a small cut was made of about 3-5 $\mathrm{mm}$ in the rear neck and the catheters were subcutaneously guided using a Hemostat (Ultra Fine Curved). A single continuous suture closed the wound (5/0 Prolene, Ethicon). The ends of the catheters were taped together to avoid destruction by biting and scratching. All surgical instruments were steam-sterilized daily and bead-sterilized before each surgery following the first.

\subsubsection{Post-operative care}

Animals were placed on a heat pad $\left(\sim 39^{\circ} \mathrm{C}\right)$ under constant observation until full recovery of consciousness. Rats were subcutaneously injected with 0.01 $0.05 \mathrm{mg} / \mathrm{kg}$ Buprenorphine (CCMS) bi-daily on 3 consecutive days after surgery and checked for bleeding, infections and excessive weight loss ( $>20 \%$ bodyweight) or general signs of sickness. If anything of the aforementioned occurred, animals were euthanized with $\mathrm{CO}_{2}$ according to $\mathrm{NIH}$ guidelines. 


\subsubsection{Euglycemic pancreatic clamp protocol}

\section{Baseline period}

\section{Clamp period}

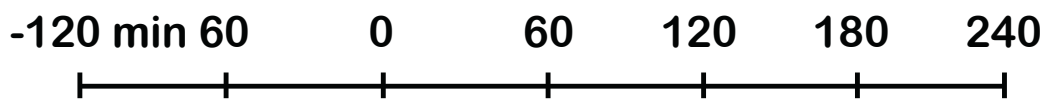

\section{MBH brain infusion}

\section{Tracer infusion}

\section{Insulin}

\section{Somatostatin}

Glucose as needed

Figure 1: Overview. Study outline consisted of a 4 hour baseline period followed by a 2 hour clamp period. Protocol could be adjusted as needed. (c) C. Buettner

Rats were required to recover to within $10 \%$ of the pre-surgical body weight (BW) in order to become subject of the experiment. The rat was placed in a new cage with bedding and allowed $\sim 15$ minutes to habituate.

\section{Catheter Syringe Preparation}

a. For the arterial catheter: Attach a luer stub, made by blunting a 23 gauge needle, to one end of $75 \mathrm{~cm}$ of PE 50 tubing. To the other end, attach a catheter coupler made from a doubly blunted 23 gauge needle.

b. $\quad$ For the venous catheter: Attach a luer stub, made by blunting a 20 gauge needle, to one end of $75 \mathrm{~cm}$ of PE 90 tubing. To the other end, attach a catheter coupler made by blunting a 20 gauge needle and pulling it out of the plastic luer piece.

2. Flush both pieces of tubing through with heparinized saline $(40 \mathrm{U} / \mathrm{ml})$ from $10 \mathrm{ml}$ syringes.

3. To prevent rats from biting tubing, thread arterial and venous tubing through a plastic guard created by cutting the tip of a $1 \mathrm{ml}$ syringe cylinder. 
4. Preparation of stereotaxic infusion

a. Fill a Hamilton glass syringe with $\mathrm{d}-\mathrm{H} 2 \mathrm{O}$, avoiding any bubbles in the syringe.

b. Prepare a piece of PE50 tubing long enough to reach from the pump to the rat by attaching an infusion cannula to one end, and a 23 gauge luer stub (described in 1a) to the other. Flush the tubing through with water and insert the Hamilton syringe into the needle, there must not be any air in the infusion system at this point. Flush out any remaining water from the system.

c. Aspirate $1 \mu \mathrm{L}$ of air into the tubing to separate the $\mathrm{d}-\mathrm{H} 2 \mathrm{O}$ from the treatment, and then aspirate the desired treatment.

d. Secure syringe to pump and prime the infusion system.

\section{Connecting Catheters}

a. Carefully, expose catheters without irritating the rat.

b. Clamp tubing, remove venous catheter plug and insert catheter coupler attached to syringe (described above in 1). Draw back blood until it reaches the syringe, and flush so that the tubing is filled with heparinized saline and no blood.

c. Repeat with arterial catheter. Once flushed, clamp arterial catheter syringe tubing with a hemostat.

d. Remove dummy cannula and insert the primed infusion cannula to the stereotactically implanted guide cannula. Secure the infusion cannula to the guide with glue. Generally, the rats do not have to be restrained during these procedures.

\section{Blood Sampling}

a. Hold all syringes upright to avoid air bubble injection.

b. Draw back blood from the arterial catheter until it reaches the tip of the catheter syringe. Clamp the line with hemostat, remove the syringe, and replace it with a $1 \mathrm{ml}$ syringe ("Dead Volume" syringe). 
c. Draw back $0.5 \mathrm{ml}$ of blood (the dead volume), then insert a new syringe (the "Sample" syringe) and take a sample.

d. Immediately re-inject dead volume, flush catheter and clamp with hemostat.

e. Collect blood into an EDTA coated tube. Measure glucose (Analox GM9D, London, United Kingdom) and centrifuge for 2 min. to collect plasma, saving $150 \mu l$ for use in the insulin preparation described below (Step 8).

f. Resuspend remaining blood cells in saline and reinject after each sample to minimize overall blood loss.

7. Start brain infusion and timer $(t=-120 \mathrm{~min})$. Protocol outline depicted in figure 2.

8. Solution preparations

a. Insulin Solution, based on an infusion rate of $25 \mu \mathrm{L} / \mathrm{min}$ : prepare $5 \mathrm{ml}$ of insulin mixture in a $10 \mathrm{ml}$ syringe with a 23 Gauge luer stub consisting of:

i. $\quad 150 \mu \mathrm{L}$ plasma (5\% plasma solution, to prevent insulin from sticking to PE tubing),

ii. Insulin Dose, calculated as follows: BW $(\mathrm{kg})$ * insulin dose $(\mathrm{mU} / \mathrm{kg} / \mathrm{min}) * 200$ (conversion factor) $=\mu \mathrm{L}$ of insulin from a 1 $\mathrm{mU} / \mathrm{ml}$ insulin stock,

iii. $\quad 3 \mu \mathrm{g} / \mathrm{kg} / \mathrm{min}$, calculated as follows: BW $(\mathrm{kg})$ * 1200 (conversion factor $)=\mu l$ of a $0.5 \mu \mathrm{g} / \mu \mathrm{l}$ somatostatin stock,

iv. Add saline to reach a total volume of $5 \mathrm{ml}$.

b. Glucose: Prepare about $3 \mathrm{ml}$ of $25 \%$ glucose in a $10 \mathrm{ml}$ syringe with a 23 Gauge luer stub.

c. Tracer.

9. Prepare the Infusion Tubing outlined in Figure 2. Prime glucose, insulin, and tracer lines and clamp each with hemostat.

a. Prepare catheter coupler (as in 1b) to connect PE50 tubing to PE90 venous tubing and insert to Infusion Tubing. 
b. Draw back blood into the venous catheter to visualize successful infusion and connect the Infusion Tubing to venous catheter.

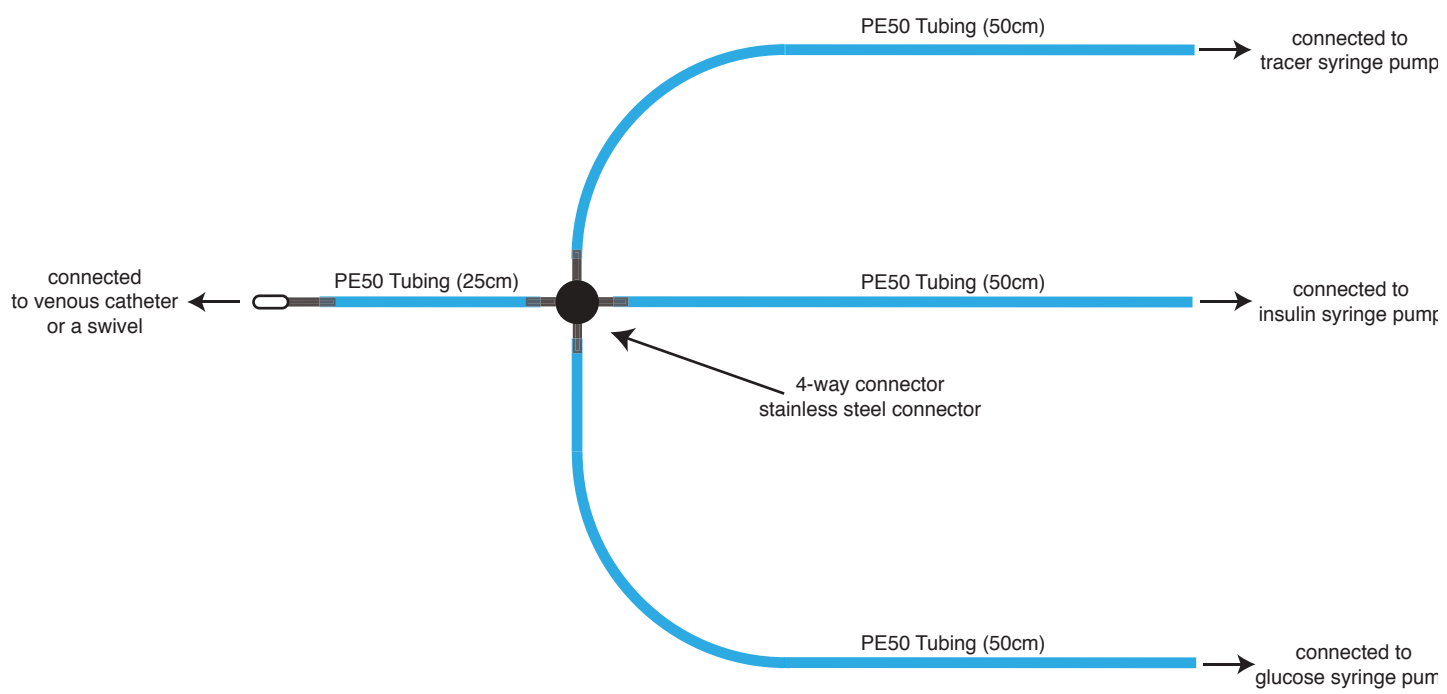

Figure 2: $\quad$ Schematic outline for tubing preparation. (C) C. Buettner

10. Collect a pre-clamp blood sample ( $\mathrm{t}=120 \mathrm{~min})$. Begin infusions by starting pumps and unclamping each line.

a. Insulin infusion begins at a rate of $44 \mu \mathrm{L} / \mathrm{min}$ for 1 minute, followed by $25 \mu \mathrm{L} / \mathrm{min}$ until the end of the clamp.

b. Set Glucose Pump rate according to insulin dose. For example, a $1 \mathrm{mU}$ clamp starts at $3 \mu \mathrm{L} / \mathrm{min}$.

c. Tracer infusion is initiated at $\mathrm{t}=0 \mathrm{~min}$.

11. Monitor blood glucose every 10-15 min and adjust Glucose Pump rate accordingly. Glucose infusion rate (GIR) is calculated based on BW and pump rate as shown in the equation. Collect samples when desired.

$$
\operatorname{GIR}\left(\frac{m g}{B W(k g) \times \min }\right)=\frac{\text { Infused Glucose }(\mathrm{g} / \mathrm{L}) \times \text { Pump rate }(\mu \mathrm{L} / \mathrm{min})}{B W(k g) \times 1000}
$$

12. Terminate clamp by injecting rat with ketamine slowly IV. 


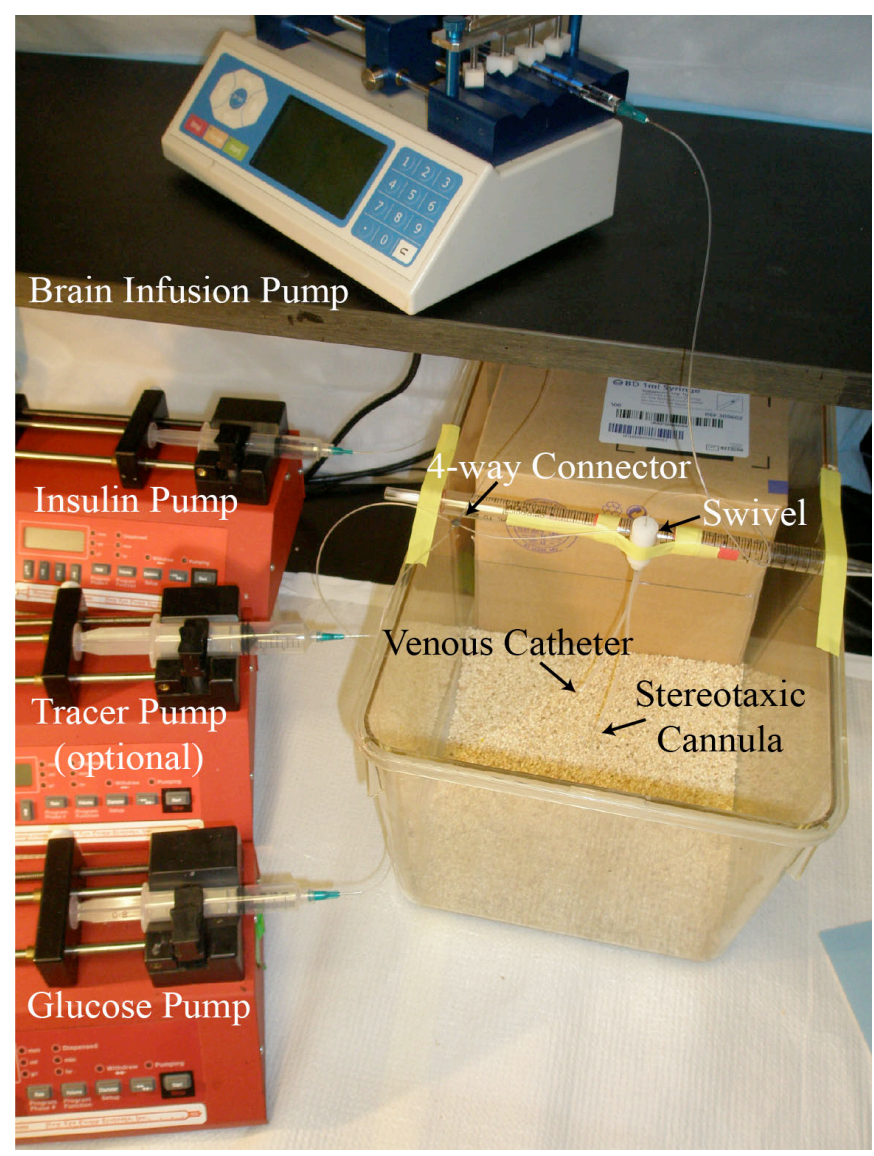

Figure 3: Clamp setup. Here we depict the setup utilizing an optional 2-channel swivel. (C) C. Buettner

Table 1: Specific reagents and equipment.

\begin{tabular}{|l|l|l|l|}
\hline Name of equipment & Company & $\begin{array}{l}\text { Catalogue } \\
\text { Number }\end{array}$ & Comments (optional) \\
\hline Luer Stub 20 G & BD & BD305175 & $\begin{array}{l}\text { made from Precision } \\
\text { Guide 20 G needle }\end{array}$ \\
\hline Luer Stub 23 G & BD & BD305193 & $\begin{array}{l}\text { made from Precision } \\
\text { Guide 23 G needle }\end{array}$ \\
\hline Luer Stub 23 G for head infusion & Instech & LS23 & BD305175 \\
\hline Catheter Couplers 20 G & BD & $\begin{array}{l}\text { made from Precision } \\
\text { Guide 20 G needle }\end{array}$ \\
\hline Catheter Couplers 23 G & BD & BD305193 & $\begin{array}{l}\text { made from Precision } \\
\text { Guide 23 G needle }\end{array}$ \\
\hline $\begin{array}{l}\text { PE 50 (0.58mm) Polyethylene } \\
\text { Tubing }\end{array}$ & $\begin{array}{l}\text { Intramedic } \\
\text { Clay Adams } \\
\text { Brand }\end{array}$ & $1417012 B$ & \\
\hline $\begin{array}{l}\text { PE 90 (0.86mm) Polyethylene } \\
\text { Tubing }\end{array}$ & $\begin{array}{l}\text { Intramedic } \\
\text { Clay Adams } \\
\text { Brand }\end{array}$ & $1417012 \mathrm{D}$ & \\
\hline Flexible Silicone Tubing & Instech & BSIL-T015 & 0.015 "ID x 0.078"OD \\
\hline
\end{tabular}




\begin{tabular}{|c|c|c|c|}
\hline 4-way Connector & $\begin{array}{l}\text { Ziggy's } \\
\text { Tubes and } \\
\text { Wires }\end{array}$ & $\begin{array}{l}\text { Custom } \\
\text { made }\end{array}$ & \\
\hline 3-way Connector & $\begin{array}{l}\text { Ziggy's } \\
\text { Tubes and } \\
\text { Wires }\end{array}$ & $\begin{array}{l}\text { Custom } \\
\text { made }\end{array}$ & \\
\hline $1 \mathrm{~mL}$ Syringe w/ Luer-Lok & BD Syringe & BD309602 & \\
\hline 10 mL Syringe w/ Luer-Lok & BD Syringe & BD309604 & \\
\hline $20 \mathrm{~mL}$ Syringe w/ Luer-Lok & BD Syringe & BD309661 & \\
\hline $\begin{array}{l}1700 \text { Series Gastight } 50 \mu \mathrm{L} \\
\text { Syringe }\end{array}$ & Hamilton Co & $60376-048$ & \\
\hline Infusion Cannula System & $\begin{array}{l}\text { Plastics One } \\
\text { Inc. }\end{array}$ & & $\begin{array}{l}\text { Consisting of guide } \\
\text { cannula, dummy } \\
\text { cannula and infusion } \\
\text { cannula }\end{array}$ \\
\hline Swivel- 2 Channel & $\begin{array}{l}\text { Plastics One } \\
\text { Inc }\end{array}$ & & \\
\hline Bulldog Serrefine Clamp, Curved & $\begin{array}{l}\text { Fine Science } \\
\text { Tools Inc. }\end{array}$ & $18051-50$ & \\
\hline $\begin{array}{l}\text { Hemostat (Schwartz Temporary) } \\
\text { Clamp }\end{array}$ & $\begin{array}{l}\text { Biomedical } \\
\text { Research } \\
\text { Instruments }\end{array}$ & $14-1360$ & \\
\hline Brain Infusion Pump & Chemyx, Inc & Fusion 400 & \\
\hline Infusion Pumps & $\begin{array}{l}\text { New Era } \\
\text { Pump } \\
\text { Systems, Inc }\end{array}$ & NE-300 & \\
\hline Somatostatin $25 \mathrm{mg}$ & $\begin{array}{l}\text { Bachem } \\
\text { Biosciences } \\
\text { Inc. }\end{array}$ & $\mathrm{H}-1490.0025$ & \\
\hline D-(+)-Glucose Solution (45\%) & $\begin{array}{l}\text { Sigma- } \\
\text { Aldrich Inc. }\end{array}$ & $\begin{array}{l}\text { G8769- } \\
100 \mathrm{~mL}\end{array}$ & \\
\hline
\end{tabular}

\section{Tissue storage}

As mentioned previously, tissues were clamp frozen in liquid nitrogen and stored at $-80^{\circ} \mathrm{C}$. 


\subsection{Analytical methods}

\subsubsection{Liquid scintillation counting}

In order to evaluate glucose uptake as well as endogenous glucose production (eGP), we used a continuous $\left[3-{ }^{3} \mathrm{H}\right]$-glucose infusion as previously described. Blood samples for scintillation counting were drawn at appropriate time points for each experiment. The resulting plasma samples as well as tracer (diluted 1:10 with saline) were transferred to a fume hood to comply with radiation safety. Measurement of diluted total tracer activity was crucial as it accounted for auto-radiolysis occurring in radioactive chemical compounds.

To each eppendorf tube, containing either $25 \mu \mathrm{L}$ of diluted tracer or blood plasma, $50 \mu \mathrm{L}$ of $0.3 \mathrm{~N}$ Zinc Sulfate and $50 \mu \mathrm{L} 0.3 \mathrm{~N}$ Barium Hydroxide solution (both Sigma-Aldrich, St. Louis, MO) were added using a repeater pipette (Eppendorf, Hamburg, Germany) to deproteinate the samples. After briefly flicking the tubes, samples were centrifuged (Eppendorf, Hamburg, Germany) at $13,000 \mathrm{rpm}$ for $5 \mathrm{~min}$. $35 \mu \mathrm{L}$ of the supernatant was then pipetted into a 96 well plate for scintillation counting. To eliminate tritiated water the supernatant was dried overnight and reconstituted with water the morning after. Before counting $200 \mu \mathrm{L}$ of Ultima Gold was added to each well, which were then covered with adhesive plate sealer and aluminum foil and placed on a rotating shaker for several hours (3-30 hours). For liquid scintillation counting the MicroBeta TriLux including proprietary software were used to assess counts per minute (cpm) per well. Specific activity of plasma glucose (cpm per mg blood plasma glucose) was then calculated and used to determine the glucose turnover rate from using its ratio to the $\left[3-{ }^{3} \mathrm{H}\right]$-glucose tracer infusion rate.

During the pre-clamp steady state conditions, eGP equals the glucose turnover rate. While eGP has to be calculated by subtracting the GIR from the glucose turnover rate during the pancreatic clamp period, the glucose turnover rate equals the rate of glucose disposal under steady state conditions. 


\begin{tabular}{|c|c|c|c|c|c|c|c|}
\hline Time (min) & $\begin{array}{l}\text { Glucose } \\
\text { (mg/dL) }\end{array}$ & $\begin{array}{l}\text { Pump Rate } \\
\text { (uL/min) }\end{array}$ & $\begin{array}{c}\text { GIR (mg/min/ } \\
\mathrm{kg})\end{array}$ & Counts (cpm) & $\begin{array}{c}\text { Specific } \\
\text { Activity (cpm/ } \\
\text { mg) }\end{array}$ & GU & GP \\
\hline 0 & 112 & & & 6 & & & \\
\hline 60 & 104 & & 0.00 & 992 & 37923 & 9.0 & 9.0 \\
\hline 80 & 104 & & 0.00 & 1079 & 41269 & 8.3 & 8.3 \\
\hline 90 & 104 & & 0.00 & 1023 & 39115 & 8.8 & 8.8 \\
\hline 100 & 99 & & 0.00 & 1026 & 41212 & 8.3 & 8.3 \\
\hline 110 & 101 & & 0.00 & 1043 & 41069 & 8.3 & 8.3 \\
\hline 120 & 95 & & 0.00 & 1176 & 49263 & 6.9 & 6.9 \\
\hline 150 & 85.5 & 13 & 11.44 & 879 & 40842 & 8.4 & -3.1 \\
\hline 180 & 112.5 & 13.5 & 11.88 & 947 & 33458 & 10.2 & -1.7 \\
\hline 190 & 118 & 13 & 11.44 & 1004 & 33831 & 10.1 & -1.3 \\
\hline 200 & 117 & 13 & 11.44 & 945 & 32103 & 10.7 & -0.8 \\
\hline 210 & 122 & 13 & 11.44 & 894 & 29115 & 11.8 & 0.3 \\
\hline 220 & 121 & 12.5 & 11.00 & 906 & 29752 & 11.5 & 0.5 \\
\hline 230 & 121 & 12.5 & 11.00 & 935 & 30711 & 11.1 & 0.1 \\
\hline \multirow[t]{2}{*}{240} & 120 & 12.5 & 11.00 & 728 & 24067 & 14.2 & 3.2 \\
\hline & & & 0.00 & 0 & & & \\
\hline
\end{tabular}

$$
\begin{array}{cc}
\text { Total Tracer }(\mathrm{cpm}) \\
65790 & \text { Average } \\
55750 & 60770
\end{array}
$$

Tracer Infusion Rate (cpm/ kg/min)

\begin{tabular}{|l|r|}
\hline GIR & 11.33 \\
\hline Rd & 11.5 \\
\hline GP Basal & 8.5 \\
\hline GP Clamp & 0.3 \\
\hline$\%$ Supp. & $96.2 \%$ \\
\hline
\end{tabular}

Basal $\quad 342366$

Clamp $\quad 342366$

Figure 4: Examplary spreadsheet of scintillation counting calculations in Microsoft Excel. ( $G U=$ glucose uptake or Rate of disappearance $(\mathrm{Rd}), \mathrm{GP}=$ glucose production)

If not stated otherwise, all supplies for the liquid scintillation counts were purchased from Perkinelmer, Waltham, MA.

\subsubsection{Stable-isotope tracer}

The plasma rate of appearance ( $\mathrm{Ra}$ ) for glycerol and leucine was measured using plasma samples from 120 (basal), 180 and 240 (clamp) time points. While the Ra for glycerol reflects systemic lipolysis, the Ra of leucine serves as an index for endogenous whole body proteolysis (Heiling et al. 1993, Scherer et al. 2011).

By using the following equation we were able to calculate the Ra based on the infusion rate ( $R$ in $\mu \mathrm{mol} / \mathrm{kg} / \mathrm{min}$ ) and fractional isotopic enrichment of the

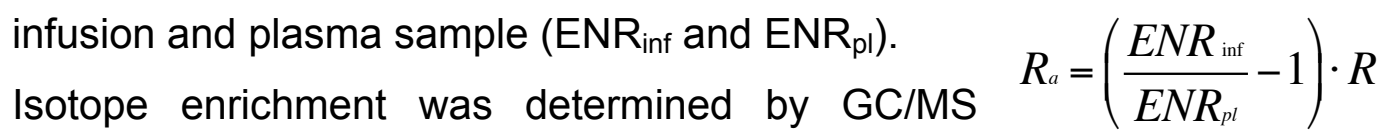
(realized by Michelle Puchowicz, Case Western Reserve University, $\mathrm{OH}$ ). 


\subsubsection{Tissue preparation}

In general, tissue preparation and handling were conducted at cryogenic temperatures using liquid nitrogen and dry ice to prevent thawing and degradation of the tissue until protease inhibitors and appropriate buffers are added.

For tissue homogenization in preparation for analysis of amino acids, acylcarnitines, organic acids, and acyl coenzyme, liver samples were pulverized using a liquid-nitrogen-chilled 3-pound sledge hammer by placing the samples in a pre-chilled pouch made out of extra heavy duty aluminum foil. Pulverized tissue was afterwards stored at $-80^{\circ} \mathrm{C}$ until homogenization.

Before homogenization the liver samples were weighed and placed on dry ice. For preparation of tissue samples for western blot analyses, lysis buffer was added to tissue samples according to table 2 .

\begin{tabular}{|c|l|l|l|l|l|}
\hline Tissue & Liver & \multicolumn{2}{|l|}{ Hypothalamus } & Muscle & Fat \\
\hline Weight & $100 \mathrm{mg}$ & Big & Small & $100 \mathrm{mg}$ & $\begin{array}{l}100 \mathrm{mg}(200 \mathrm{mg} \\
\text { obese animals) }\end{array}$ \\
\hline Tube & $5 \mathrm{ml}$ & $2 \mathrm{ml}$ & $2 \mathrm{ml}$ & $5 \mathrm{ml}$ & $2 \mathrm{ml}$ \\
\hline $\begin{array}{c}\text { Lysis } \\
\text { buffer }\end{array}$ & $1 \mathrm{ml}$ & $100 \mu \mathrm{L}$ & $80 \mu \mathrm{L}$ & $500 \mu \mathrm{L}$ & $500 \mu \mathrm{L}$ \\
\hline
\end{tabular}

Table 2: $\quad$ Amount of lysis buffer to be added per individual tissue

High-performance liquid chromatography (HPLC) grade water $(450 \mu \mathrm{L})$ per $50 \mathrm{mg}$ tissue or $1900 \mu \mathrm{L}$ per $100 \mathrm{mg}$ tissue and an equal mixture of isopropanol and $0.1 \mathrm{M} \mathrm{KH}_{2} \mathrm{PO}_{4}$ (all Sigma-Aldrich, St. Louis, $\mathrm{MO}$ ) were added to pulverized liver samples, later on subjected to mass spectrometry.

Irrespective of the assay, samples were homogenized (Tissue Tearor, BioSpec Products, Inc., Bartlesville, OK) for 20 seconds. In between two samples, the homogenizer was washed with ethanol and rinsed twice with deionized water $\left(\mathrm{dH}_{2} \mathrm{O}\right)$.

Mass spectrometry samples were refrozen and send out to our collaborator for analyses (Metabolomics Laboratory, Sarah W. Stedman Nutrition \& Metabolism Center, Duke University Medical Center, Raleigh, NC). 
Samples for western blotting analyses were sonicated (Sonifier 250, Branson Ultrasonics Corporation, Danbury, CT) at the lowest setting for additional 15 seconds, cleaning the sonicator in between samples with ethanol once and twice with $\mathrm{dH} 2 \mathrm{O}$. The tubes were then transferred to a cooled centrifuge (Eppendorf, Hamburg, Germany) at $4^{\circ} \mathrm{C}$ (Fat: $0^{\circ} \mathrm{C}$ ) and spun down for 20 min at $13,000 \mathrm{~g}$. The resulting supernatant was afterwards transferred to $1.5 \mathrm{ml}$ eppendorf microtubes and stored on ice.

Lysis buffer was prepared using $40 \mathrm{mM}$ beta glycerophosphate, $2 \mathrm{mM}$ sodium orthovanadate, 20mM 3-(N-morpholino)propanesulfonic acid (MOPS), 30mM sodiumflouride, $10 \mathrm{mM}$ sodium pyrophosphate, $2 \mathrm{mM}$ ethylene glycol tetraacetic acid (EGTA), 5mM Ethylenediaminetetraacetic acid (EDTA) and 1Lof deionized water as solvent (all purchased from Sigma-Aldrich, St. Louis, MO). One tablet of light sensitive protease inhibitor (Roche, Nutley, NJ) was added to $50 \mathrm{ml}$ of buffer in an aluminum wrapped tube before use.

\subsubsection{Protein assay}

The protein assay served as a crucial tool for adjustment of different total protein concentrations and allowed us to evaluate specific enzyme levels and their activity, respectively. We used the Pierce bicinchoninic acid (BCA) Protein Assay Kit (Thermo Scientific, Waltham, MA) to determine the total protein concentration. After successful tissue preparation, the aforementioned supernatant of each sample was pipetted to a 96 well plate as shown in table 2 and diluted with water according to its tissue of origin (shown in table 4). Bovine serum albumin (BSA, Sigma-Aldrich, St. Louis, MO) was used as protein standard and diluted (BSA A-H in table 3 ) to calculate total protein concentrations. 


\begin{tabular}{|l|l|l|l|l|l|l|}
\hline & \multicolumn{1}{|c|}{$\mathbf{2}$} & \multicolumn{1}{|c|}{$\mathbf{2}$} & \multicolumn{1}{c|}{$\mathbf{4}$} & \multicolumn{1}{|c|}{$\mathbf{6 - 1 2}$} & \multicolumn{1}{|c|}{} \\
\hline A & BSA A & BSA A & Sample 1 & Sample 1 & Water & \\
\hline B & BSA B & BSA B & Sample 2 & Sample 2 & Water & \\
\hline C & BSA C & BSA C & Sample 3 & Sample 3 & Buffer & \\
\hline D & BSA D & BSA D & Sample 4 & Sample 4 & Buffer & \\
\hline E & BSA E & BSA E & Sample 5 & Sample 5 & & \\
\hline F & BSA F & BSA F & Sample 6 & Sample 6 & & \\
\hline G & BSA G & BSA G & Sample 7 & Sample 7 & & \\
\hline H & BSA H & BSA H & Sample 8 & Sample 8 & & \\
\hline
\end{tabular}

Table 3: $\quad$ Sample plate layout for a protein assay for 8 samples.

\begin{tabular}{|c|c|c|c|c|}
\hline & Liver & Hypothalamus & Muscle & Fat \\
\hline dH2O & $19 \mu \mathrm{l}$ & $18 \mu \mathrm{l}$ & $18 \mu \mathrm{l}$ & $18 \mu \mathrm{l}$ \\
\hline Sample & $1 \mu \mathrm{l}$ & $2 \mu \mathrm{l}$ & $2 \mu \mathrm{l}$ & $2 \mu \mathrm{l}$ \\
\hline BSA & $20 \mu \mathrm{l}$ & $20 \mu \mathrm{l}$ & $20 \mu \mathrm{l}$ & $20 \mu \mathrm{l}$ \\
\hline
\end{tabular}

Table 4: $\quad$ Sample volumes for different tissue (adjustment if total protein concentrations are not in between BSA standard concentrations).

The BCA protein assay reagent formed by mixing reagent $A$ and $B$ at a ratio of $50: 1$ and $200 \mu \mathrm{L}$ was added to each sample containing well. The plate was sealed and and incubated at $37^{\circ} \mathrm{C}$. After 30 mins the plate was put on ice for 1 min and inserted in our spectrophotometer (Multiskan ${ }^{\circledR}$ Spectrum, Thermo Scientific, Waltham, MA), measuring absorbance at a wavelength of $620 \mathrm{~nm}$.

Average standard BSA levels were measured and a linear trendline was plotted, which allowed us to determine the total protein concentration of our samples. The coefficient of determination $\mathrm{R}^{2}$ was determined using Microsoft Excel built- in -function and accepted if $R^{2}$ was 0.99 or above (Example shown in figure 5). 


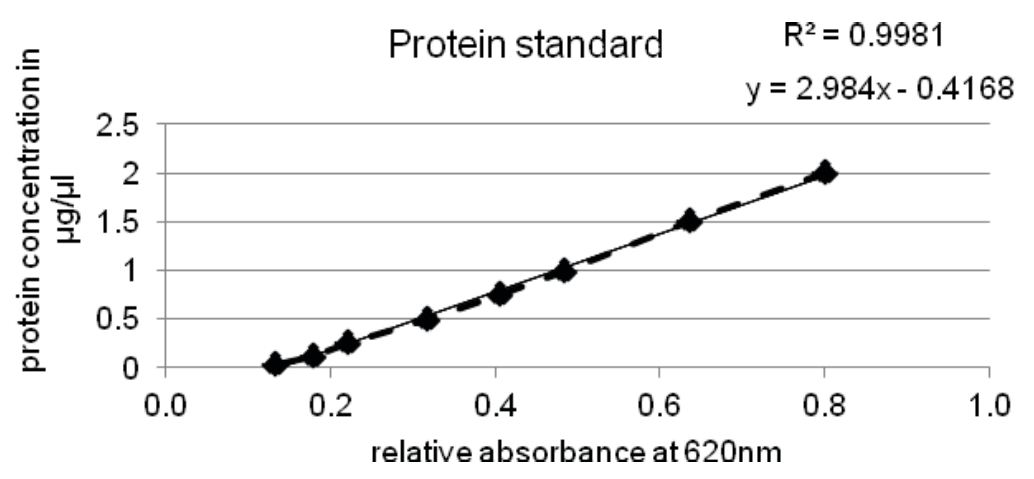

Figure 5: $\quad$ Sample protein standard curve.

After determination of the concentration, samples were diluted with lysis buffer to a final concetration of $3-4 \mu \mathrm{g} / \mu \mathrm{L}$ total protein for western blot analysis.

\subsubsection{Western blotting}

Western blotting allowed us to measure key enzymes in treated animals and compare their relative quantity to that in control groups, reflecting the in vivo up- or down-regulation of those proteins and/or their phosphorylation and therefore activated or inactivated state during the experiment.

It consists out of several steps starting with gel electrophoresis (running the gel), transfer of proteins to a membrane (the actual blot or transfer), application of specific primary antibodies (ABs) to desired proteins (primary antibodies) and probing the membrane with secondary ABs against primary ABs for visualization. Dependent on the amount of light emitted after excitation the relative quantity could be calculated, since it is directly proportional to the emitted light of a specific wavelength (direct fluorescence measurement at 680 and $800 \mathrm{~nm})$.

\section{Gel electrophoresis}

Our usual electrophoresis setup consisted out of precast $4-12 \%$ NuPage $®$ gels, XCell SureLock $®$ electrophoresis chambers, NuPage $®$ MOPS sodium dodecyl sulfate (SDS) Running Buffer, NuPage ${ }^{\circledR}$ Antioxidant and a ZOOM $®$ Dual Power Supply (all Invitrogen, Carlsbad, CA).

Diluted samples were mixed with loading buffer $(93.3 \mu \mathrm{L}$ buffer per $200 \mu \mathrm{L}$ sample) to denature and reduce the proteins. Samples were then heated 
(Accublock, Labnet International, Woodbridge, NJ) to $85^{\circ} \mathrm{C}$ for 5 minutes and put on ice. Each well of the gel was then flushed and filled with the prepared sample ideally yielding a total protein load of $20 \mu \mathrm{g}$. A protein marker (Odyssey Protein Molecular Weight Marker 10-250 kDA, LI-COR, Lincoln, $\mathrm{NE}$ ) was added to later on identify proteins based on their molecular weight. The marker as well as the dyed bands of each sample helped us to determine an even separation between samples, as ideally all samples built a horizontal line at the bottom of the gel after an electrophoresis. It usually took 2 hours at 110 volts to successfully run each electrophoresis experiment.

\section{Transfer}

To transfer the proteins, blot membranes (Immobilon FL PVDF, Millipore, Billerica, MA) were cut, labeled, rinsed with methanol and stored in transfer buffer 10 to 20 min before end of the gel electrophoresis. Then gels and membrane were carefully placed in between filter paper and soaked in transfer buffer. Transfer buffer soaked sponges were put around the gelmembrane sandwich and put into a transfer chamber (XCell II Blot Module, Invitrogen). After filling the chamber with transfer buffer, the front and rear parts of the tank were filled with ice to cool the chamber during the transfer. The transfer itself usually took another 2 hours at 200mA followed by blocking the membranes at room temperature for 1 hour using Odyssey LI-COR Blocking Buffer (LI-COR, Lincoln, NE) 1:1 diluted in TBS.

Membranes were then put into tubes containing the desired primary ABs and incubated at $4^{\circ} \mathrm{C}$ overnight.

\section{Scanning and analysis}

The morning after, each membrane was washed three times for 5 minutes with TBS-T $(0.1 \%)$ on a rocking shaker. Following the third wash, blots were incubated for $1 \mathrm{hr}$ at room temperature in $15 \mathrm{ml}$ blocking buffer containing $0.1 \%$ TBS-T and $0.1 \%$ SDS, Dylight 680 -conjugated goat anti-rabbit IgG and Dylight 800-conjugated goat anti-mouse IgG (both Thermo Scientific, Waltham, MA). Since the secondary antibodies are light sensitive, the washing boxes were covered with aluminum foil during the incubation. Following three washes with TBS-T and final wash with TBS, blots were 
analyzed for fluorescence. For direct fluorescence measurement and quantification we used the LI-COR Odyssey scanner (LI-COR, Lincoln, NE) and Odyssey 3.0 software. Protein identification was based on molecular weight, antibodies used and color (red or green), as non-specific bands appeared in some used antibodies. After quantification we normalized each sample to corresponding housekeeping (GAPDH, $\alpha$-tubulin or $\beta$-actin) that was not altered by treatment to adjust for possible unequal loading volumes and built the ratio to the control group for enhanced visualization of the percentage change.

\section{Reagents}

All reagents were purchased from Sigma-Aldrich if not mentioned otherwise.

Loading buffer:

TBS-T:

TBS:

Transfer buffer:

Blocking buffer:

Primary antibody:

20x TBS:

10x Transfer buffer: $\quad 300 \mathrm{~g}$ tris base $+1500 \mathrm{~g}$ glycine $+10 \mathrm{l} \mathrm{dH} 2 \mathrm{O}$

$5 \mathrm{ml}$ NuPage ${ }^{\circ}$ LDS sample buffer $4 \mathrm{x}+2 \mathrm{ml}$ NuPage $\AA$ sample reducing agent 10x (stored at $4^{\circ} \mathrm{C}$, both Invitrogen, Carlsbad, CA)

1l of $20 x$ TBS +19 l of $\mathrm{dH} 2 \mathrm{O}+20 \mathrm{ml}$ of Tween ${ }^{\circledR}$.

$500 \mathrm{ml}$ of $20 \mathrm{x}$ TBS $+9.5 \mathrm{l}$ of $\mathrm{dH} 2 \mathrm{O}$

1l 10x Transfer Buffer $+7 \mathrm{I}$ of $\mathrm{dH} 20+2$ I methanol

$25 \mathrm{ml}$ blocking buffer (LI-COR, Lincoln, NE) $+25 \mathrm{ml}$ of $1 x$ TBS (1:1)

Blocking buffer and $1 \mathrm{x} \mathrm{TBS} / \mathrm{T}$ at $1: 1$ ratio. Add antibody to get recommended dilution.

Example: Cell Signaling AB: $2.5 \mathrm{ml}$ blocking buffer $+2.5 \mathrm{TBS} / \mathrm{T}+5 \mu \mathrm{l} \mathrm{AB}$. $(1: 1000)$

Secondary antibody: $\quad 50 \mathrm{ml}$ TBS/T $+50 \mu$ l SDS $10 \%+8.3 \mu$ l anti-rabbit $(1: 6000)+6.3$ ul anti-mouse $(1: 8000$, both Thermo Scientific, Waltham, MA) $484 \mathrm{~g}$ tris base $+1600 \mathrm{~g} \mathrm{NaCl}+10 \mathrm{ldH} 2 \mathrm{O}+\mathrm{HCl}$ to $\mathrm{pH}$ of 7.6 


\section{Primary antibodies}

Antibodies against the following proteins mentioned in this thesis are:

Acetyl-CoA carboxylase (ACC), $\alpha$ subunit of AMP-activated protein kinase (AMPK $\alpha$ ), Ampk $\alpha$ Thr 172 phosphorylated (pAMPK, all Cell Signaling Technology, Beverly, MA), Fatty acid synthase (FAS, BD Bioscience, San Jose, CA), $\alpha$-tubulin, $\quad \beta$-actin and Glyceraldehyde 3-phosphate dehydrogenase (GAPDH, all Abcam, Cambridge, MA)

\subsubsection{Assays}

Free fatty acids (FFAs, NEFAs), triglycerides (TG) and free-glycerol were measured in plasma using a colorimetric enzyme linked assay by Wako Chemicals (Richmond, VA) and Sigma-Aldrich (St. Louis, MO).

\section{Free-glycerol and triglyceride assay}

The serum triglyceride determination kit allowed us to measure free-glycerol as well as total triglyceride concentration in one assay, which measured glycerol concentration through a chain of enzymatic reactions (figure 6, adapted from kit insert) resulting in a dye. The dye's absorbance is directly proportional to the plasma glycerol concentration, either deriving from freeglycerol or triglycerides. As plasma triglycerides are bound to proteins, lipoprotein lipase (triglyceride reagent) was added in order to break down triglycerides into glycerol and fatty acids.

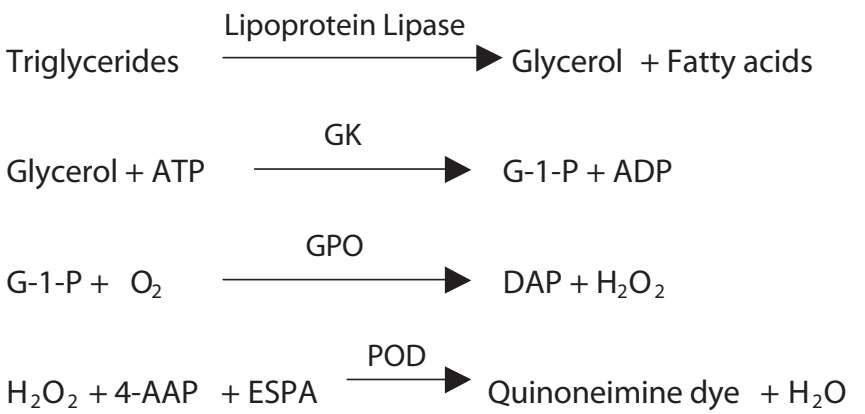

Figure 6: $\quad$ Triglyceride assay schematics
The spectrophotometer was set to a wavelength of $540 \mathrm{~nm}$ and calibrated to zero with water. Then a 96 well plate with blank, sample and standard wells each containing free glycerol reagent was prepared and water, sample or glycerol standard added accordingly. After incubating the plate for 5 minutes 
at $37^{\circ} \mathrm{C}$ we read out our initial measurement of absorbance (IA), added triglyceride reagent and incubated the plate for another 5 minutes. Final absorbance (FA) was measured and concentrations were calculated by division of $I A_{\text {sample }}-I A_{\text {blank }}$ and $I A_{\text {standard }}-I A_{\text {blank }}$ multiplied with the concentration of the standard for free-glycol concentration. For triglyceride concentration we repeated the calculation with FA instead of IA readings.

\section{Free fatty acid assay}

Similar to the previous assay, NEFA levels were determined by measuring the absorbance of a dye (figure 8, adapted from kit insert) directly proportional to

NEFA levels. For
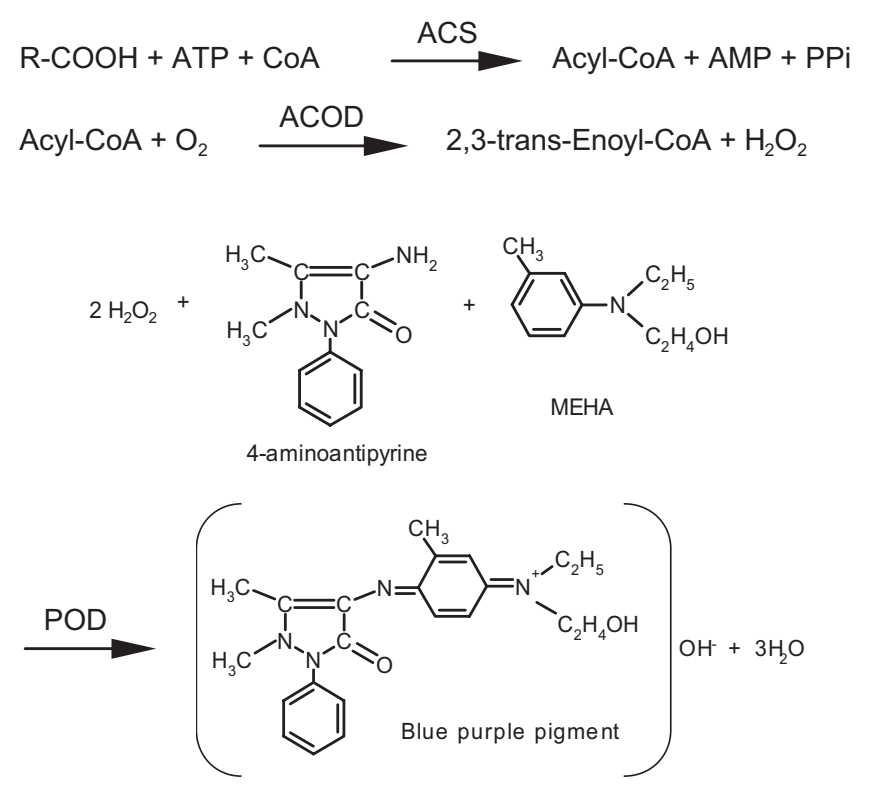

Figure 7: NEFA assay schematics calibration we used the NEFA standard from Wako Chemicals (Richmond, VA). The spectrophotometer was set to $550 \mathrm{~nm}$ at $37^{\circ} \mathrm{C}$. $300 \mu \mathrm{L}$ of Color Reagent A Solution were added to $7 \mu \mathrm{L}$ per sample and used as sample blank. Then $150 \mu \mathrm{L}$ of Color Reagent B Solution were added and the sample absorbance was measured after 4.5 mins. Concentrations were calculated in mmol using a standard curve for NEFA as described for the protein assay.

\section{Glutamate-dehydrogenase activity assay}

Glutamate-dehydrogenase catalyzes the reaction from glutamate to $\alpha$ ketoglutarate and vice versa. By artificially oversaturating glutamate in the samples, we were able to measure the enzymes activity through the elevation of Nicotinamide adenine dinucleotide (NADH), a coenzyme of the reaction, which was measured colorimetrically $(\lambda=450 \mathrm{~nm})$. Contrary to the previous 
assays, this activity assay measures the signal multiple times in short intervals so a kinetic curve could be plotted. Where the activity was higher, the substrate was exhausted more quickly and only that part of the curve that resembled a linear function numerically was chosen for further analyses. The average activity and specific activity was then calculated based on the absorbance of NADH standard solutions included in the used kit (BioVision, Mountain View, CA). Due to the proprietary nature of the kit, a detailed description of its ingredients was not available upon request (link current as of April $26^{\text {th }}$ 2013: http://www.biovision.com/glutamate-dehydrogenase-activitycolorimetric-assay-kit-4019.html).

\subsubsection{Metabolomics analysis}

To detect various metabolites in liver and plasma samples provided by us, a stable-isotope dilution followed by either flow-injection tandem-mass spectrometry (MS-MS) for amino acids (AAs) and acylcarnitines (ACs), or gas chromatography-mass spectrometry (GC/MS) for organic acids (OAs) was used (Ferrara et al. 2008, Turer et al. 2009). Acyl-CoA metabolites were assessed by solid-phase extraction followed by flow-injection mass spectrometry (Monetti et al. 2007). Internal standards for AAs, ACs and OAs were labeled with heavy stable isotopes while acyl-CoA analysis was based on spiking with C17 coenzyme A. Metabolomics analysis was performed in the Sarah W. Stedman Nutrition \& Metabolism Center under the direction of Christopher B. Newgard, PhD.

\section{Mass spectrometer}

A mass spectrometer (MS) consists of three essential components, the ionization source, the mass analyzer and the detector. The sample is first introduced into the ionization source where the molecules are ionized before being separated by electromagnetic fields and detected based on their mass $(\mathrm{m})$ to charge $(\mathrm{z})$ ratio $(\mathrm{m} / \mathrm{z})$ spectra. To ensure unhindered separation, analyses are usually conducted in a vacuum. Each molecule (ion) has a distinct $\mathrm{m} / \mathrm{z}$ ratio by which it can be identified. Biological samples however, contain a plethora of different molecules, which makes it difficult to reliably identify each of them by MS alone, so the samples need to be separated 
before introduction to the ionization source (gas chromatography, high pressure liquid chromatohraphy) or broken down further after a first reading (tandem-MS).

\section{Tandem mass spectrometer}

A tandem mass spectrometer usually has two analyzers that are separated by a collision cell into which an inert gas, such as xenon is admitted to collide with the sample ions and fragment them. The ions characteristic fragmentation pattern improves the reliability of identification.

\section{Gas chromatography}

As explained earlier, several methods for pre-separation are available. The method primarily used in our studies was gas-liquid chromatography. Its principle is based on an inert gas carrying the vaporized sample, called mobile phase and a layer of liquid inside a tube called stationary phase. As the gaseous mixture flows through the tube (column), the mobile phase interacts with the stationary phases in the column, which leads to the elution of each component at a different time called retention time. By analyzing each components specific elution and retention time, a first qualitative detection of most molecules can be made before entering the mass spectrometer.

\section{Solid-phase extraction}

Analog to gas chromatography, solid-phase extraction consist of a mobile and a stationary phase with the difference that the mobile phase is liquid while the stationary phase is solid. After passage of the mobile phase through a cartridge containing the stationary phase, either the solid or liquid extract is kept, dependent on which extract contains the desired components.

\section{Flow-injection}

Flow-injection is an automated method to increase precision of the otherwise manual injection of a sample into a flow through detector system such as a mass spectrometer. 


\section{Stable-isotope dilution}

For highly reliable quantification of metabolites, a stable-isotope dilution method was used. Stable-isotope standards are added to the analyte and equilibrated before being subjected to MS-MS or GC/MS, thereby allowing quantitative analyses.

While doing experiments for mass spectrometry we did not use radioactive tracer, as radioactive isotopes could potentially lead to contamination of the MS. We decided to repeat experiments with radioactive tracer at a later time point, to increase group size ( $n=4$ per group for non-radioactive samples) and further investigate glucose metabolism in $\mathrm{MBH}$ leptin treated animals. 


\section{Results}

\subsection{Basic data}

Differences in bodyweight, age or glucose levels could heavily affect metabolism or the reaction to a stimulus, such as central leptin or insulin. Therefore animals were matched based on these parameters and plasma glucose levels were balanced as accurately as possible. A pancreatic clamp serves as the experimental gold-standard for evaluation of peripheral insulin sensitivity/resistance. It allows the investigator to simulate defined insulin and glucose levels, while measuring glucose uptake and production via tracer

\begin{tabular}{cccc|} 
Stable isotope tracer & MBH aCSF & MBH ins & MBH lep \\
\hline Group size & $3-4$ & 4 & 4 \\
Age (weeks) & $10.8 \pm 0.3$ & $10.5 \pm 0.1$ & $10.9 \pm 0$ \\
Bodyweight $(\mathrm{g})$ & $274 \pm 5$ & $274 \pm 7$ & $307 \pm 20$ \\
Plasma glucose $(\mathrm{mg} / \mathrm{dl})$ & $128 \pm 8$ & $122 \pm 3$ & $126 \pm 4$ \\
& & & \\
Radioactive tracer & $\mathrm{MBH}$ aCSF & MBH lep \\
\hline Group size & 7 & $4-5$ \\
Age (weeks) & $11.3 \pm 0.1$ & $11.6 \pm 0.2$ \\
Bodyweight $(\mathrm{g})$ & $326 \pm 11$ & $311 \pm 7$ & \\
Plasma glucose $(\mathrm{mg} / \mathrm{dl})$ & $130 \pm 4$ & $120 \pm 7$ &
\end{tabular}

Table 5: Bodyweight, average plasma glucose, age and group size of the different groups used for this study

dilution techniques, without interference from the endocrine part of the pancreas, which is disabled by continuous infusion of somtatostatin.

As depicted in table 5 , in each experiment two or three different groups were

examined, and consisted of one control group (MBH aCSF) and one or two treatment groups. All rats were 10-12 weeks old at the time of the clamp and weighed around $300 \mathrm{~g}$. Although the $\mathrm{MBH}$ aCSF and $\mathrm{MBH}$ ins groups seem lighter than the MBH lep group in the stable tracer experiment, no significant differences could be found.

During the course of the clamp, glucose levels were monitored and adjusted to euglycemic levels, as necessary.

Elevated GIR could be a first sign of suppressed endogenous or hepatic glucose production and is shown in the following figures as average over the entire clamp period as well as average per measured time point. Interestingly the GIR of the stable tracer group are higher compared to the radioactive 
tracer group receiving the same treatments (figure $8 \mathrm{C}, \mathrm{F}$ ). This observation can be explained by the overall higher glucose levels in the stable tracer group.
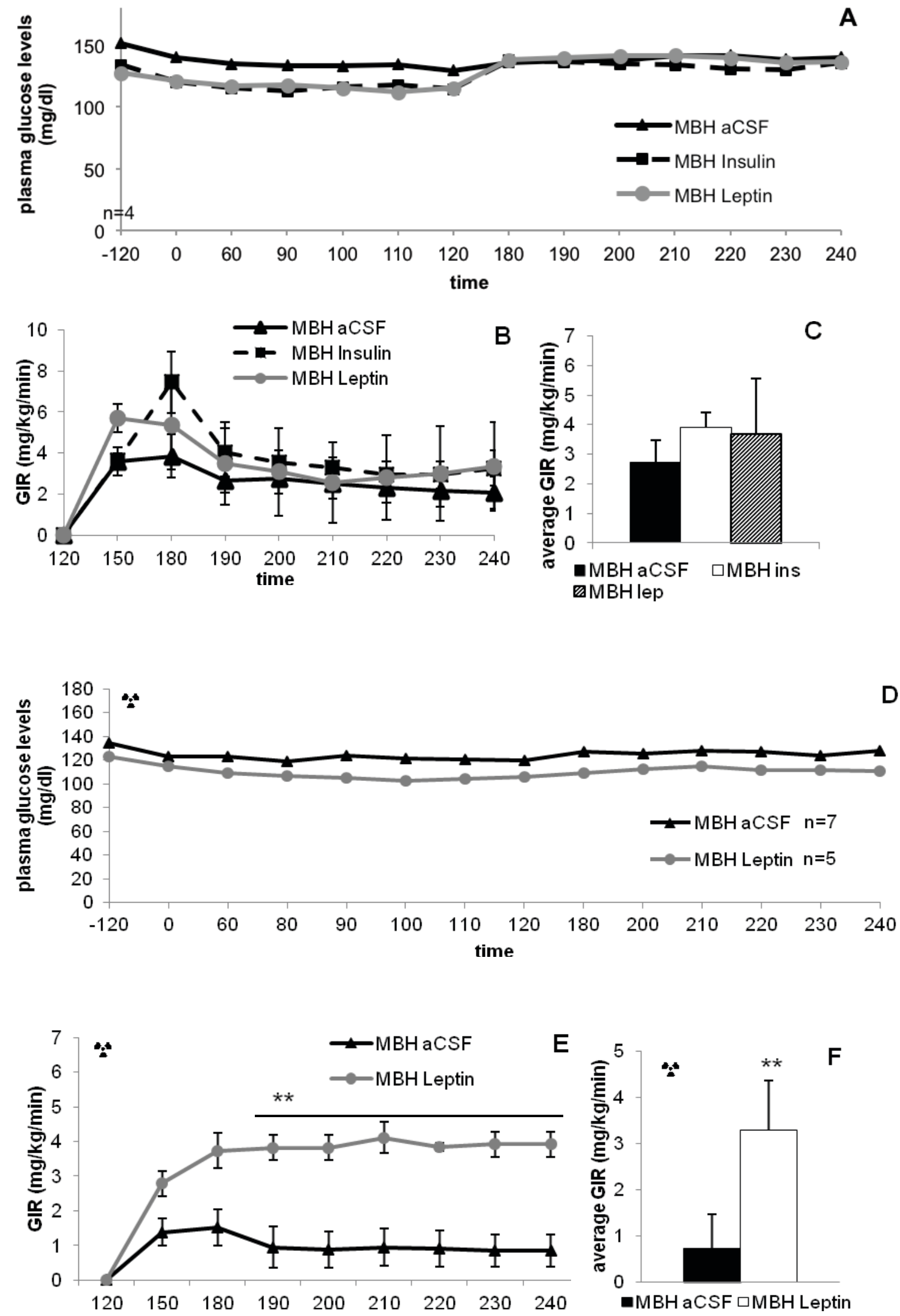
Figure 8 A-F: Plasma glucose levels in $\mathrm{mg} / \mathrm{dl}$ and glucose infusion rate in $\mathrm{mg} / \mathrm{kg} / \mathrm{min}$ are shown as mean \pm standard error of the mean (SEM). Experiments conducted with radioactive tracer are labeled with a radioactivity sign in the upper right corner $\left({ }^{*} \mathrm{P}<0.05 ;{ }^{* *} \mathrm{P}<0.01\right.$, student's two-tailed unpaired t-Test)

As shown in figure $8 \mathrm{E}$ and $\mathrm{F}, \mathrm{GIR}$ of the leptin treated animals is markedly increased compared to the control group. Nonetheless the same effect was not seen in the group receiving stable tracer (figure $8 \mathrm{~B}$ and $\mathrm{C}$ ).

\subsection{Tracer calculations}

\subsubsection{Radioactive tracer}

Hepatic glucose production in the MBH leptin group remained similar to the control group in the basal period while its suppression was markedly increased during the clamp period (figure $9 \mathrm{~A} ; \mathrm{B}$ ). Rate of glucose disposal however was unaffected in both groups (figure $9 \mathrm{C}$ ).
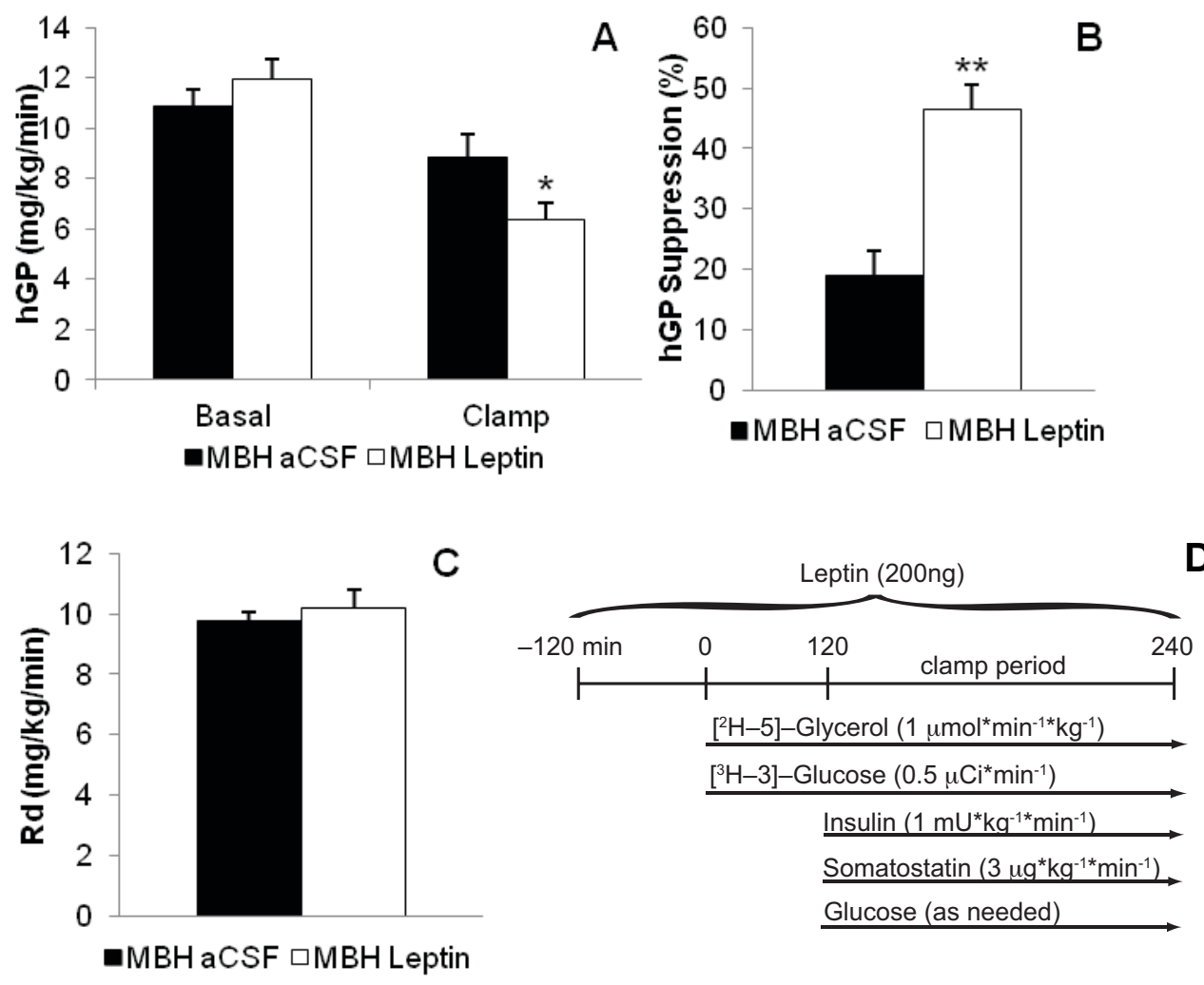

Figure 9 A-D: Hepatic glucose production (hGP), suppression of hGP, rate of glucose disposal $(\mathrm{Rd})$ and scheme for the MBH leptin treated group receiving radioactive tracer instead of stable- isotope tracer. Results shown in mean \pm SEM ${ }^{*} \mathrm{P}<0.05$, student's two-tailed unpaired $\mathrm{t}$-Test) $\mathrm{n}=7$ for $\mathrm{MBH}$ aCSF and $\mathrm{n}=5$ for $\mathrm{MBH}$ Leptin 


\subsubsection{Stable-isotope tracer}

Analysis of plasma samples containing stable-isotope tracer (figure $10 \mathrm{~A}, \mathrm{~B}$ ), showed significant decrease in Ra glycerol, indicating suppressed lipolysis, as previously described (Scherer et al. 2011). Although Ra leucine was lower in the insulin treated group it failed to reach statistical significance during the basal period by a small margin $(p=0.051)$.
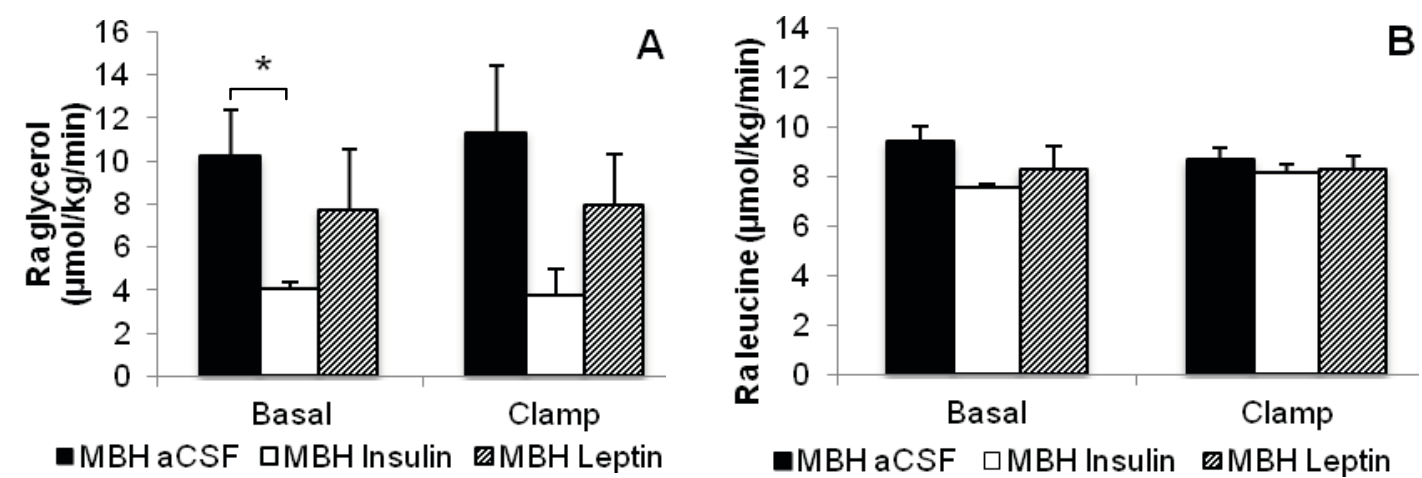

Figure $10 \mathrm{~A}, \mathrm{~B}$ : Ra glycerol and $\mathrm{Ra}$ leucine in $\mu \mathrm{mol} / \mathrm{kg} / \mathrm{min}$ and $\mathrm{mg} / \mathrm{kg} / \mathrm{min}$ respectively. Results shown in mean \pm SEM $\left({ }^{*} P<0.05\right.$, student's two-tailed unpaired $t$ Test), $\mathrm{n}=4$ 


\subsection{Triglyceride, free glycerol and NEFA plasma levels}

To properly assess energy metabolism, we determined plasma triglyceride, free glycerol and NEFA levels before start of the experiment (-120) as well as during the basal (120) and clamp (240) periods. As depicted in figure 12 neither the groups receiving stable-isotope (figure $11 \mathrm{~A}-\mathrm{C}$ ) nor the groups receiving radioactive tracer (figure $11 \mathrm{D}-\mathrm{F}$ ) showed any significant change over the course of the experiment.
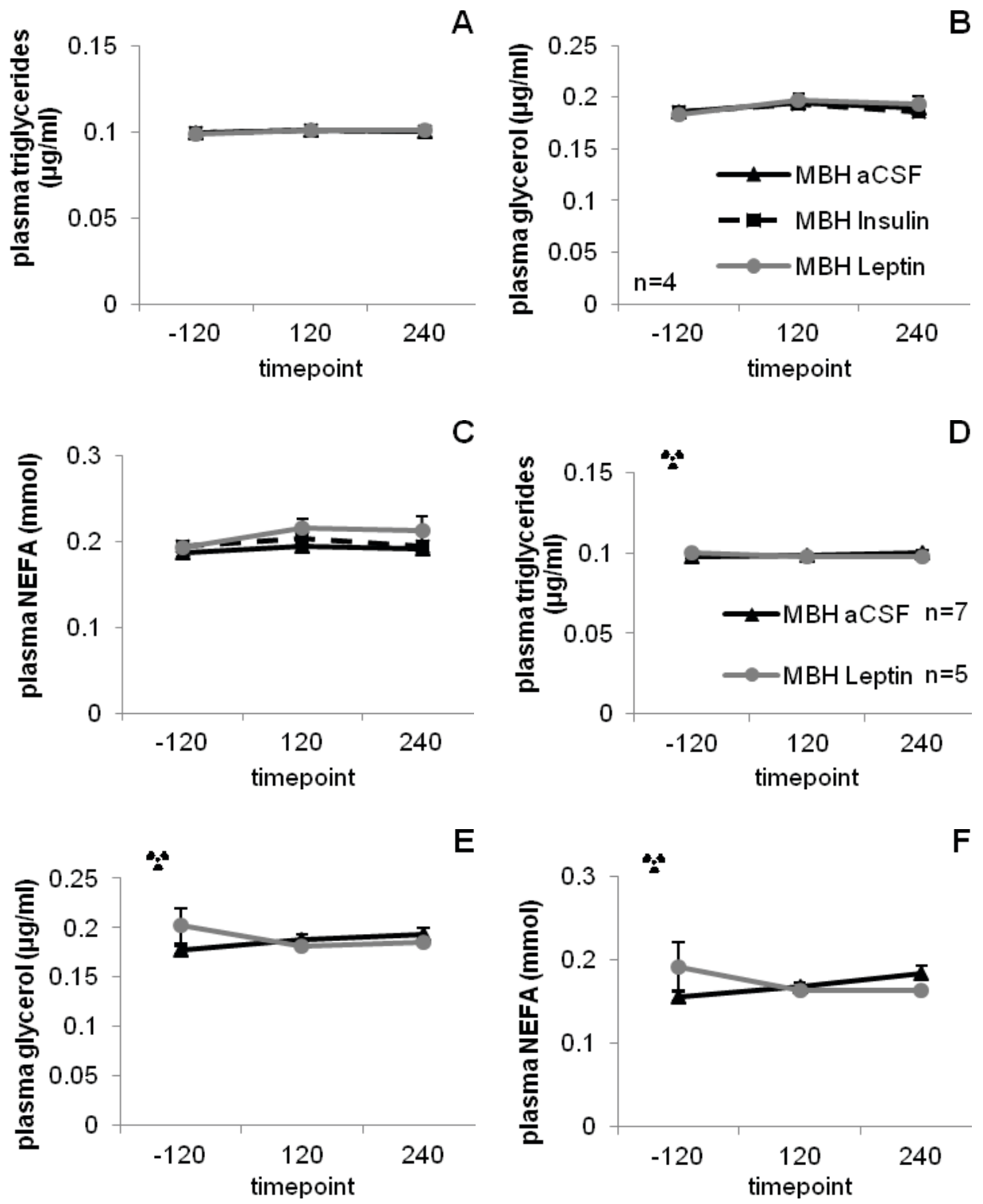

Figure 11 A-F: Plasma triglyceride, free glycerol and NEFA levels in either $\mu \mathrm{g} / \mathrm{ml}$ or mmol), $n=4$ for non-radioactive, $n=5$ for radioactive $\mathrm{MBH}$ leptin, $\mathrm{n}=7$ for radioactive $\mathrm{MBH}$ aCSF. Results shown in mean \pm SEM ( $\mathrm{P}<$ 0.05, student's two-tailed unpaired t-Test) 


\subsection{Metabolomics}

Metabolomic analyses of both liver and/or plasma samples enabled determination of the amount of acyl-CoA and acylcarnitine per sample. Results have been segregated into short chain(chain length between $\mathrm{C2}-\mathrm{C} 6$ ), medium chain(C7-C12), and long chain (C13-C22) groups to point out the most important ones separately.

\subsubsection{Plasma sample analysis}

We analyzed plasma samples from the start $(t=-120 \mathrm{~min})$ and the end $(t=$ $240 \mathrm{~min}$ ) of the experiment to separate changes in metabolites that are clamp related from changes caused by our administered treatment. The samples taken at time point $t=-120$ min were examined for significant differences between control and treatment groups.

\section{Amino Acids}

The ratio from samples taken at $t=240 \mathrm{~min}$ and $\mathrm{t}=-120 \mathrm{~min}$ was calculated and shown in figure 12. A value lower than 1 reflects a decrease over the course of the experiment, while a value above reflects an increase. As depicted in figure $12 \mathrm{~A}$ alanine as well as histidine increased in all groups, while the increase in valine, leucine/isoleucine, phenylalanine and ornithine seen in the control group could not be shown in treatment groups.

\section{Acylcarnitines}

Medium chain acylcarnitines decreased in the control group as shown in figure $12 \mathrm{~B}$, while short and long chain acylcarnitines remained unaffected. Significance was tested between control and treatment group from total plasma values at time point $t=240$ min using student's two-tailed unpaired $t$ Test. 

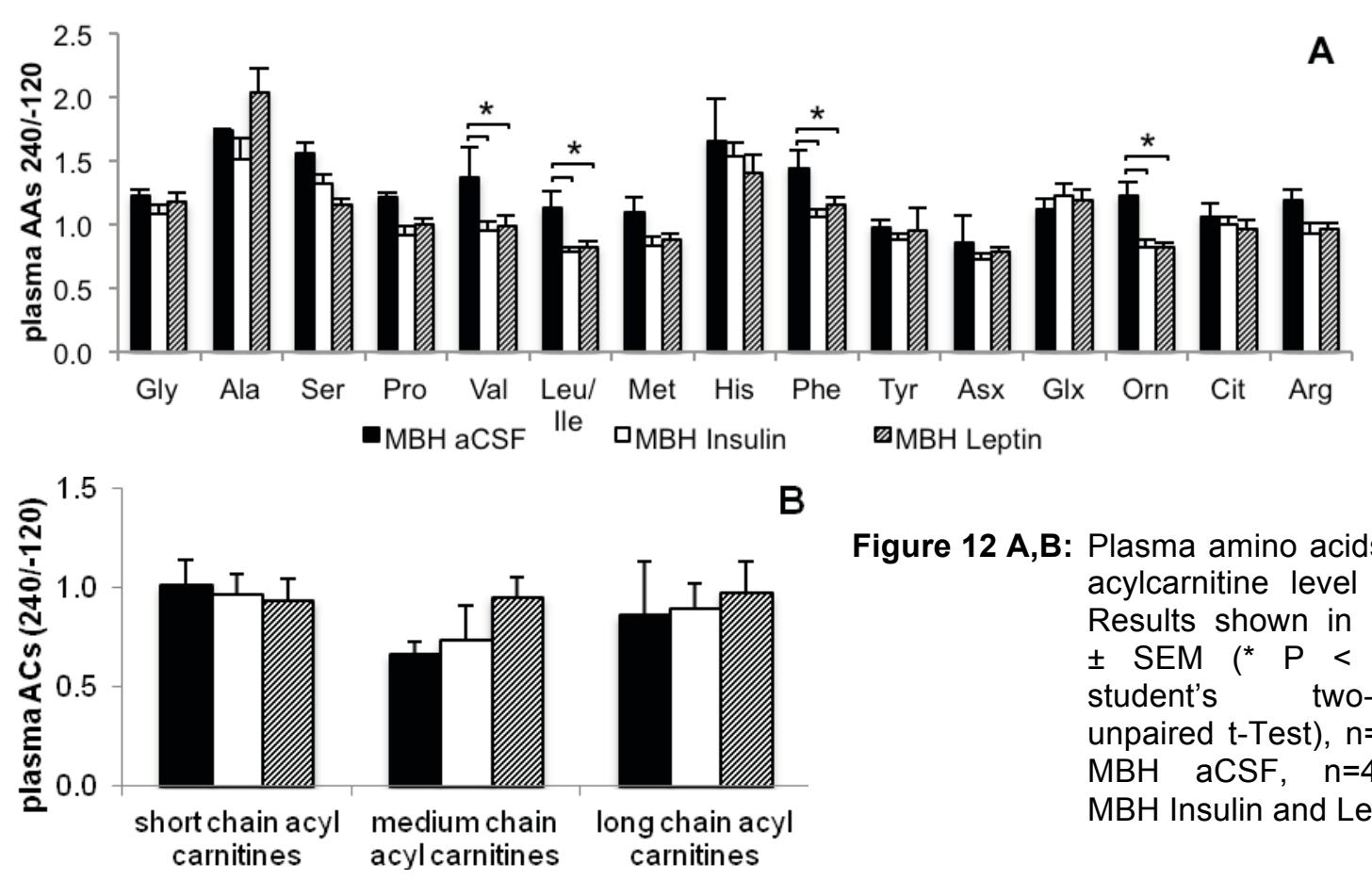

Figure 12 A,B: Plasma amino acids and acylcarnitine level ratio. Results shown in mean \pm SEM $(* \mathrm{P}<0.05$, student's two-tailed unpaired $t$-Test), $n=3$ for $\mathrm{MBH}$ aCSF, $\mathrm{n}=4$ for $\mathrm{MBH}$ Insulin and Leptin

\subsubsection{Liver sample analysis}

Metabolites from liver samples were analyzed using their concentration normalized to the control groups' metabolite concentration ( $\mu \mathrm{M}$ metabolite per $\mu \mathrm{g} / \mathrm{ml}$ total protein concentration). Alanine levels were markedly increased in the $\mathrm{MBH}$ leptin group, while glycine, methionine, histidine, tyrosine levels were moderately increased in $\mathrm{MBH}$ insulin treated animals. Phenylalanine, glutamine + glutamate levels were slightly elevated and asparagine + aspartate levels in the $\mathrm{MBH}$ leptin group showed a $50 \%$ decline in comparison to control animals (figure $13 \mathrm{~A}: \mathrm{B}$ ). Organic acid levels developed the biggest fold change in treated animals with up to 5-fold change in pyruvate and 3-fold in lactate levels. Fumarate levels were significantly higher in the $\mathrm{MBH}$ leptin group as well (figure $13 \mathrm{C}$ ). Although long chain acylcarnitine levels were up to $50 \%$ decreased, they failed to reach statistical significance. Short chain Acyl-CoA levels on the other hand expressed a significant increase in both treatment groups. The metabolically most significant CoA complexes including Coenzyme A itself are depicted in Figure 13 F. Acetyl-CoA and CoA-SH concentrations are elevated in both $\mathrm{MBH}$ insulin and leptin groups, as malonyl-CoA and succinyl-CoA are in the $\mathrm{MBH}$ leptin group. 

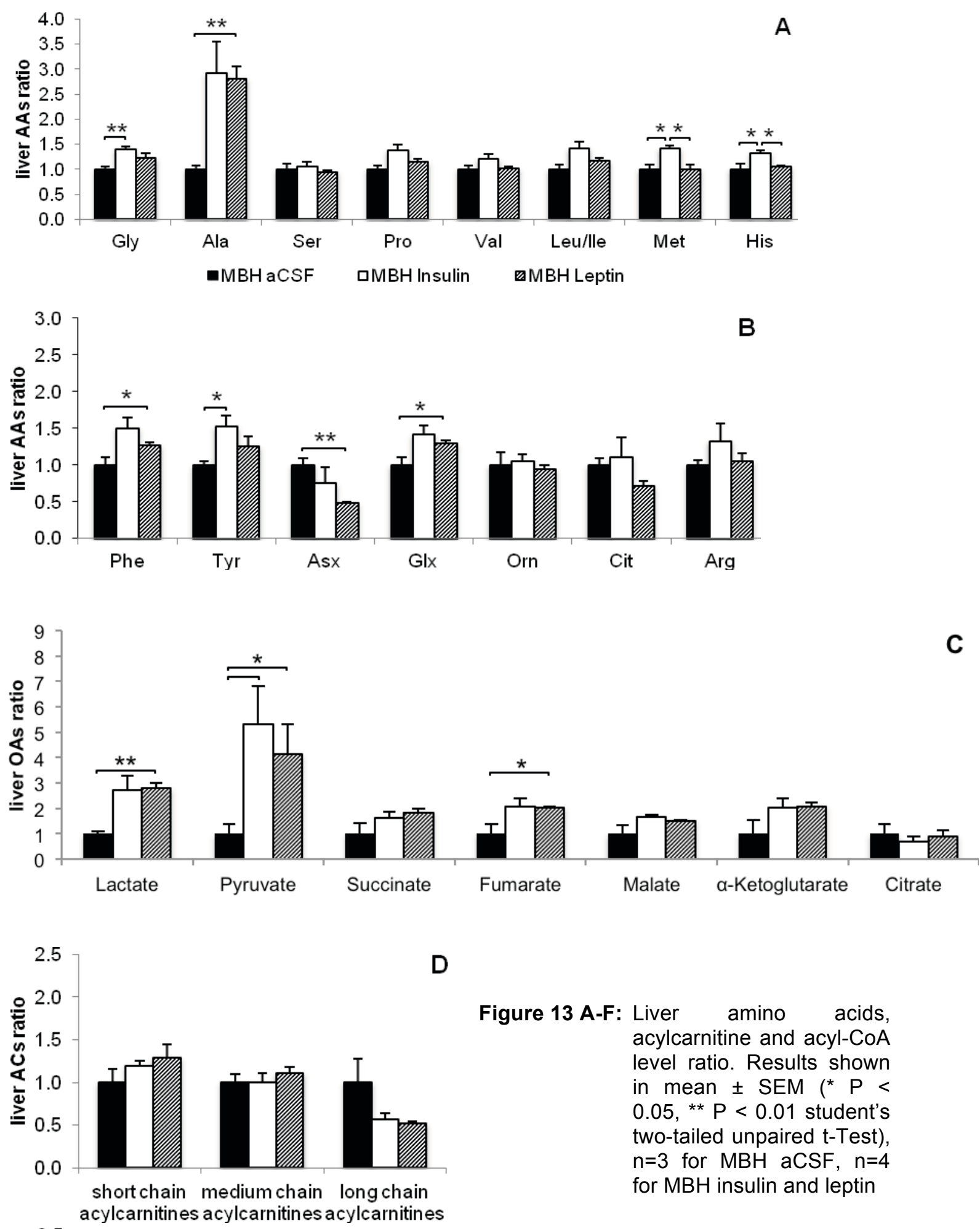

Figure 13 A-F: Liver amino acids, acylcarnitine and acyl-CoA level ratio. Results shown in mean \pm SEM (* $P$ < $0.05,{ }^{* *} P<0.01$ student's two-tailed unpaired t-Test), $\mathrm{n}=3$ for $\mathrm{MBH}$ aCSF, $\mathrm{n}=4$ for $\mathrm{MBH}$ insulin and leptin

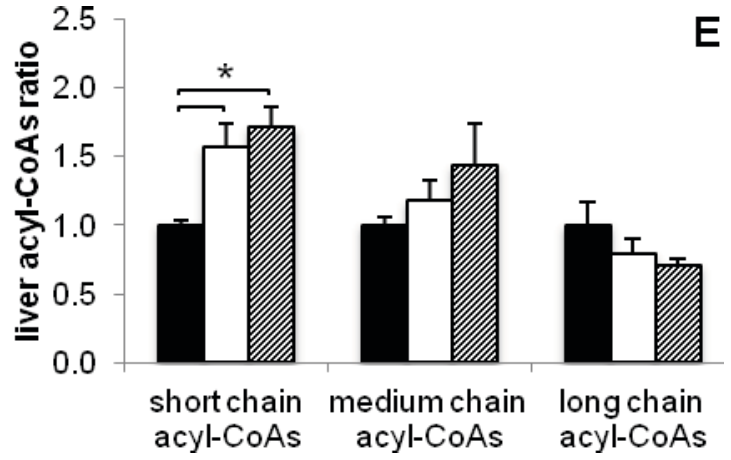




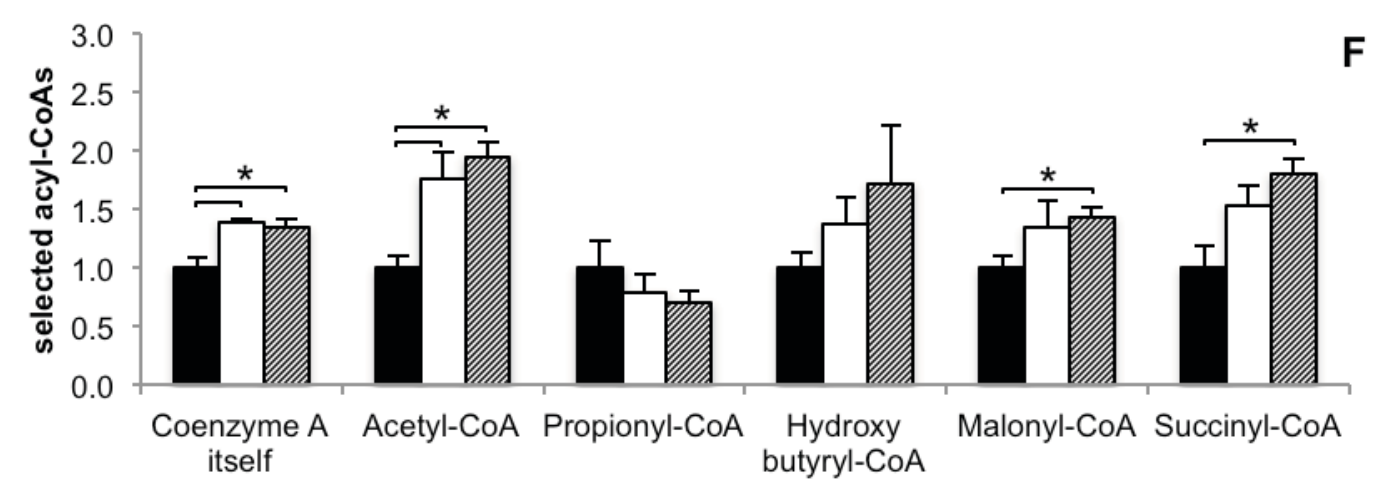

\subsection{Western Blots}

Quantification by western blot produced inconsistent data as phosphorylated

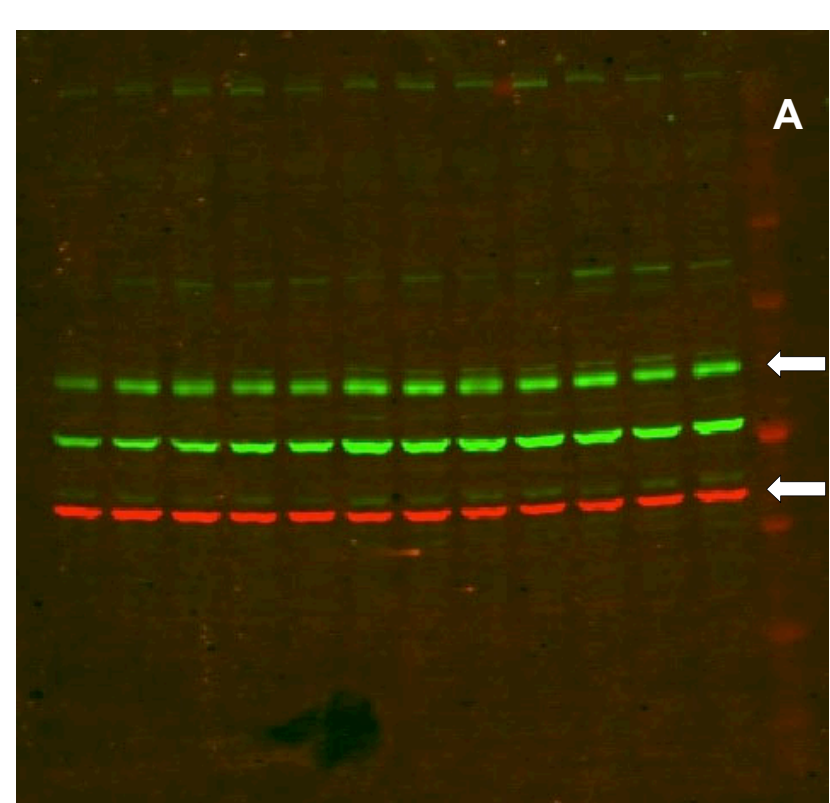
AMPK $\alpha$ and AMPK $\alpha$ increased significantly in some groups receiving stable-isotope tracer, while the same increase could not be shown in a repeated experiment using radioactive tracer (figure $14 \mathrm{~B} ; \mathrm{C}$ ). Figure 14 A shows an exemplary image of AMPK $\alpha$ and $\beta$-actin quantified in figure $15 \mathrm{~B}$. The analyzed proteins were selected based on their importance in fatty acid metabolism (Abu-Elheiga et al. 2001, Mabrouk et al. 1990, Minokoshi et al. 2002). 

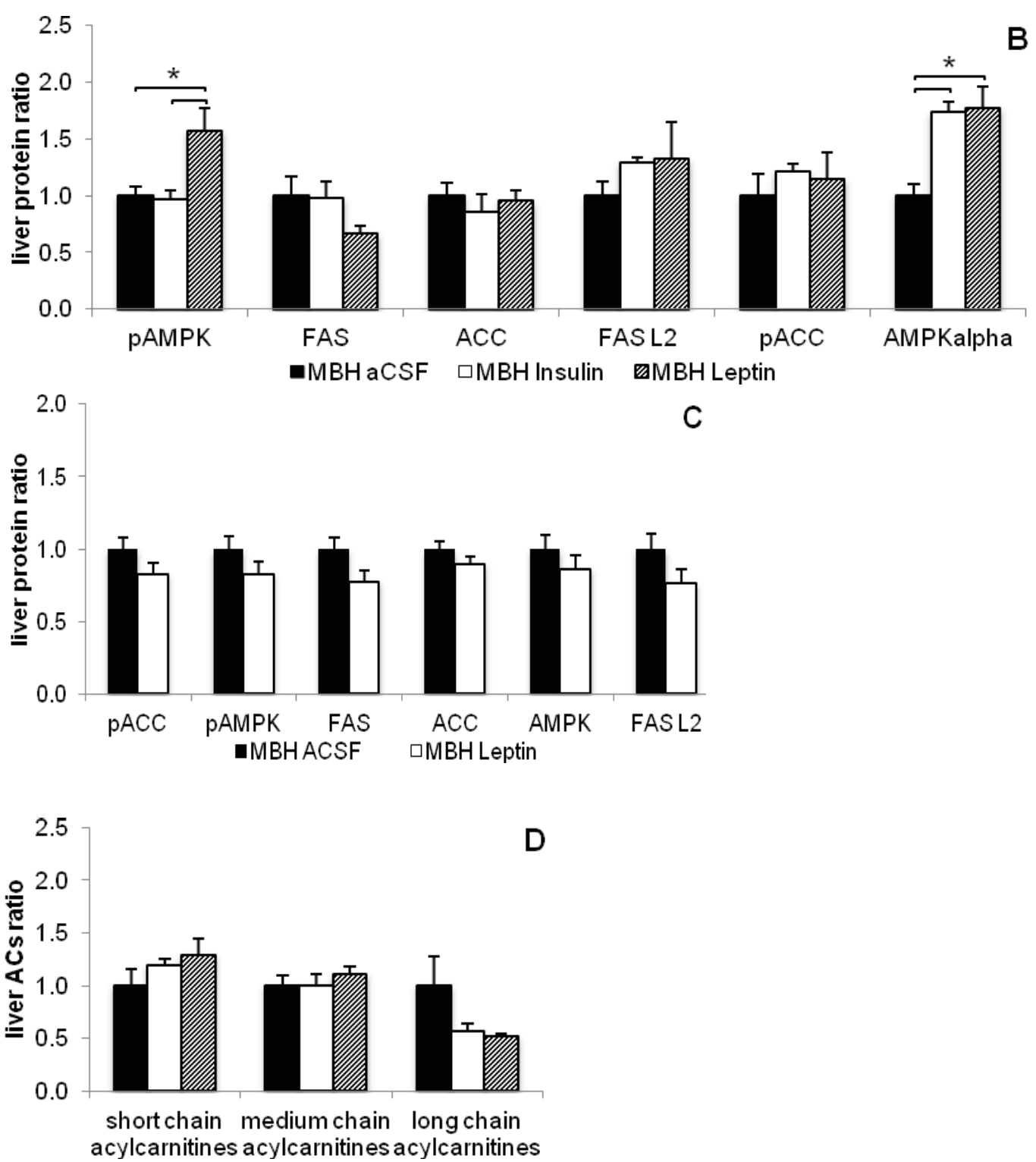

Figure 14 A-D: A: Western blot of AMPK $\alpha$ (green) and $\beta$-actin (red) indicated by white arrows, B;C: Normalized ratio of proteins analyzed by western blot. D: Normalized ratio of liver acylcarnitines. Results shown in mean \pm SEM $\left({ }^{*} P<\right.$ 0.05 , student's two-tailed unpaired t-Test, $L 2$ stands for the same $A B$ quantification on a second membrane); $B: n=4, C: n=7$ for $M B H$ aCSF, $n=5$ for $\mathrm{MBH}$ Leptin 


\subsection{Glutamate dehydrogenase activity}

We assessed the activity of GLDH which catalyzes the reaction of glutamate to $\alpha$-ketoglutarate and vice versa, and both substrates showed an increase in their liver levels (figure $13 \mathrm{~B} ; \mathrm{C}$ ). Interestingly, there was an increase of at least $50 \%$ increased activity in the $\mathrm{MBH}$ insulin group compared to control, but no increase in activity in MBH leptin treated animals

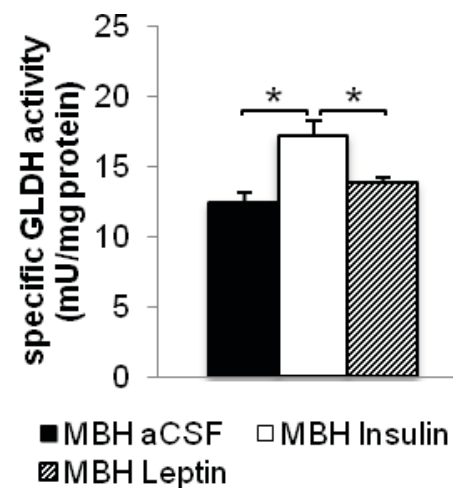

Figure 15: Specific activity of glutamate-dehydrogenase in $\mathrm{mU} / \mathrm{mg}$ protein. Results shown in mean \pm SEM ( ${ }^{*} P<0.05$, student's two-tailed unpaired t-Test), $\mathrm{n}=4$ 


\section{Discussion}

\subsection{MBH leptin and insulin ameliorate insulin resistance,} suppress long chain fatty acid oxidation in the liver and lead to a decrease in circulating BCAAs

Central leptin and insulin suppress long chain fatty acid $\beta$-oxidation in the liver and promote switch from lipid to carbohydrate and amino acid utilization.

Despite central insulin and leptin's opposing role in regulating metabolism in adipose tissue (Buettner et al. 2008, Scherer et al. 2011), their role in regulating hepatic metabolism, seems to act synergistically as supported by our results, showing a decrease in long chain acylcarnitines as well as anaplerosis of tricarboxylic acid (TCA) cycle intermediates in both treatment groups. An increase was found in both treatment groups in pyruvate, lactate and alanine that are crucial for gluconeogenesis. This accumulation of metabolites implies either a suppression of gluconeogenesis, increased glycolysis, increased hepatic uptake of those intermediates or suppression of substrates entering the TCA cycle. The concentration of these intermediates may reflect increased flux through the TCA cycle. Consistent with decreased substrate flux into the TCA cycle, we did not see an increase in liver citrate levels, but surprisingly most measured TCA cycle metabolites were either significantly elevated or showed a clear trend in both insulin and leptin treated animals compared to the vehicle group (figure $13 \mathrm{C} ; \mathrm{F}$ ), which argues against decreased flux into the TCA cycle (Koves et al. 2008), as decreased influx would result in decreased metabolite levels, while increase in metabolites could either be caused by impaired cataplerotic reactions or overall increase of flux.

Anaplerotic reactions lead to an increase of TCA cycle intermediates and usually are in balance with cataplerotic reactions, such as fatty acid synthesis and gluconeogenesis (Owen et al. 2002), that lead to a decrease in TCA cycle intermediates. Decreased gluconeogenesis or fatty acid synthesis could 
therefore account for the observed anaplerosis. The elevated Acetyl-CoA levels are in line with the overall increase of glycolysis metabolites, but could also be a consequence of suppressed fatty acid synthesis.

Cataplerotic reactions include disposal of TCA cycle intermediates to avoid accumulation (Owen et al. 2002). Such reactions are catalyzed by phosphoenolpyruvate carboxykinase (PEPCK), glutamate dehydrogenase (GLDH) or aspartate aminotransferase. We therefore analyzed GLDH activity and found a significant increase in insulin treated animals, supporting an increase in TCA cycle flux.

Whereas aforementioned intermediates (mainly glucose intermediates) homogeneously increased, intermediates specific for fatty acid metabolism differed dependent on their length and the analyzed tissue.

Short chain Acyl CoAs in liver tissue increased significantly in both treatment groups by at least $50 \%$. Medium Chain Acyl CoAs seemed to increase and long chain Acyl CoAs even decreased, but the results were not statistically significant as shown in figure $13 \mathrm{E}$.

Since Acyl CoAs occur in the cytosolic as well as in the mitochondrial fraction of the cell, it is impossible to say in which compartment the increased or decreased intermediates appear without isolation of individual subcompartments such as mitochondria or the cytosol. Carnitine Acyltransferases accelerate the reaction that is necessary for Acyl-CoAs to pass the mitochondrial membrane, by binding the acyl rest to carnitine in exchange for CoA (Ramsay et al. 2001). Therefore acylcarnitine levels can be used to estimate fatty acid flux through these membranes and lipid load of mitochondria before $\beta$-oxidation and oxidative phosphorylation (Koves et al. 2008). Short chain Acyl carnitine levels in liver tissue were slightly elevated, while medium chain Acyl carnitine levels were not altered. Long chain acylcarnitines in turn were markedly decreased (figure $13 \mathrm{D}$ ), which could be due to suppression of a rate-limiting enzyme in fatty acid $\beta$-oxidation, carnitine palmitoyltransferase 1 (CPT-1) (Doh et al. 2005). Malonyl-CoA inhibits CPT-1 activity and its level was significantly increased in leptin treated animals, supporting our theory from the observed decrease of long chain acylcarnitine 
levels, that $\mathrm{MBH}$ leptin and insulin suppress oxidative phosphorylation of long chain fatty acids in the liver.

Even chain acylcarnitines with a chain length equal to or larger than six carbon atoms derive from fatty acids, while most shorter chain length acylcarnitines and acyl-CoAs like C3 and C5 species derive from amino acid catabolism (Bhuiyan et al. 1988). Systemic administration of leptin or insulin in mice deficient of endogenous insulin was previously reported to normalize hepatic metabolite levels and might further improve DM management if given in combination (Wang et al. 2010). More specifically hepatic acylcarnitine and amino acid levels were lowered in treated animals compared to untreated diabetic rats.

Metabolite levels in pathways processing substrates from all nutrient sources (lipids, carbohydrates, amino acids) increased in $\mathrm{MBH}$ insulin or leptin treated animals, while fatty acid derived acylcarnitines in turn are markedly suppressed. This observation can be explained through preference of carbohydrate or amino acid metabolites over fatty acid metabolites in nutrient fluxes.

\section{MBH insulin alters hepatic protein synthesis}

Interestingly $\mathrm{MBH}$ insulin significantly increased liver levels of many essential amino acids like Histidine or Methionine as well as branched-chain amino acids (BCAAs).

Since most of the appearing amino acids are essential, this observation cannot be explained by increased production. One possibility would be increased proteolysis, while another one would be reduced aminoacid utilization through suppression of protein synthesis in the liver through $\mathrm{MBH}$ insulin. Since the animals were fasted before the start of the clamp, change in amino acid uptake from the gut is unlikely to account for this difference. While proteolysis usually appears in muscle tissue first (Cahill 2006, Goodman et al. 1981), one would expect a rise in the aforementioned amino acids in plasma. In fact plasma metabolite analysis showed the opposite, as most of the amino 
acids where decreased compared to control, explainable through increased utilization in peripheral tissues.

Alanine however, which is important for the transport of glucose and amino acid metabolites from muscle tissue to the liver (Felig 1973) was 1.5-2 fold increased in blood plasma after the clamp in all groups. This increase could be due to enhanced protein turnover, decrease in oxidative phosphorylation, ureageneis or gluconeogenesis (Schutz 2011) proteolysis in muscle tissue is a likely cause (since the rats transition into an early fasting state). Ra of Ileucine however did not increase, as one would expect when proteolysis occurs.

Isovalerylcarnitines (C5) in liver tissue were significantly increased in $\mathrm{MBH}$ insulin treated animals, consistent with the observed increase in amino acids and supportive for enhanced amino acid catabolism rather than suppression in protein synthesis. Consistent with the idea of increased amino acid uptake in the liver is the increase of several metabolites involved in branched-chain amino acid catabolic pathways such as glutamate, alanine, aforementioned C5-acylcarnitine and acetyl-CoA.

Overall protein synthesis in the liver might even be increased due to enhanced amino acid uptake from the bloodstream, which could explain the decreased amino acid levels we see in the plasma as well as the increased amino acid levels in liver tissue.

It is possible that proteolysis in muscle tissue occurs while amino acid uptake in the liver increases, resulting in the observed minor change in the rate of appearance of I-leucine.

As our observations in amino acid flux varied and reliable implications for protein regulation could not be made at this point, we subjected liver samples to proteomic analysis. The results of this analysis will be incorporated in a follow up study.

\section{MBH leptin and MBH insulin's effect on fatty acid synthesis in liver tissue}

Prolonged high fat feeding, a model for common forms of obesity and insulin resistance in humans leads to hypertriglyceridemia, insulin resistance, hyperinsulinemia and hyperleptinemia, the latter a manifestation of a 
compensatory response to both leptin and insulin resistance. Further, prolonged high fat feeding is known to lower fatty acid derived acylcarnitines in the liver (Koves et al. 2008), such as long and medium chain acylcarnitines, indicating decreased mitochondrial fatty acid $\beta$-oxidation, likely due to insulin resistance.

Whether the decreased long chain acylcarnitines in our model are caused only by decreased $\beta$-oxidation or also increased fatty acid synthesis remained unclear, since Malonyl-CoA was elevated predicting CPT1b inhibition, but key enzymes explaining its increase, such as PACC, ACC were not altered in western blot analysis of liver tissue (figure $14 \mathrm{~B} ; \mathrm{C}$ ). In fact the $\alpha$-subunit of AMPK, which affects numerous downstream pathways including increased fatty acid oxidation (Hardie 2004, Orci et al. 2004, Shaw et al. 2004), even showed a significant increase in animals of both treatment groups. AMPK- $\alpha$ phosphorylated at Thr 172, indicating an activated state of AMPK (Hawley et al. 1996), was only increased in the MBH leptin group (figure $14 \mathrm{~A}$ ). MalonylCoA itself inhibits CPT-1 allosterically (Brady et al. 1993) giving further proof of suppressed $\beta$-oxidation. It serves as main substrate for fatty acid synthase, whose enzyme concentration was not altered by $\mathrm{MBH}$ insulin or $\mathrm{MBH}$ leptin in western blot analysis (figure $14 \mathrm{~B} ; \mathrm{C}$ ). Due to the controversial results it was not possible to clearly assess if $\mathrm{MBH}$ leptin and insulin increase fatty acid synthesis.

\section{MBH leptin suppresses hepatic glucose production}

When we repeated the $\mathrm{MBH}$ leptin experiments previously conducted with stable-isotope tracer we were able to see a significant suppression of hepatic glucose production (figure $9 \mathrm{~B}$ )

As MBH leptin did not suppress hGP in the basal period, in fact even showed a non-significant increase, it only assisted insulin in hGP suppression during the clamp period. This observation is consistent with previous studies (Pocai et al. 2005b), implicating that central leptin is able to restore hepatic insulin sensitivity in rats receiving a high-fat diet. Pocai et al showed intracerebroventricular (ICV) leptin to increase gluconeogenesis, through upregulation of PEPCK and glucose 6-phosphatase (G6Pase), while 
decreasing glycogenolysis, resulting in no change in net hGP. In overfed rats on the other hand ICV leptin lead to a decrease of both PEPCK and G6Pase, without change of gluconeogenesis, resulting in suppression of overall hGP. By infusion into the $\mathrm{MBH}$ our study was able to further localize a region in the brain that seemed to enable leptin to decrease hGP in rats receiving regular chow. Comparison with earlier studies would therefore suggest that $\mathrm{MBH}$ leptin suppresses glycogenolysis. In fact suppression of glycogenolysis by ICV leptin is part of an $\mathrm{MSH}$ independent neuronal pathway, while gluconeogenesis is believed to be regulated through $\mathrm{MSH}$ dependent pathways (Gutierrez-Juarez et al. 2004). It is likely that our model of MBH leptin selectively regulates hGP and hepatic metabolism through $\mathrm{MSH}$ independent pathways.

$\mathrm{MBH}$ leptin did not affect insulin sensitivity in other peripheral tissues, as Rd of glucose was not affected by systemic insulin, which in part is an estimate of glucose uptake in peripheral tissues.

Central leptin in a hyperinsulinemic euglycemic pancreatic clamp setup dose dependently favored gluconeogenesis over glycogenolysis in earlier studies, but did not affect overall hGP (Liu et al. 1998). This observed decrease in hGP could be due to suppressed gluconeogenesis, which could also explain elevated levels of TCA cycle intermediates.

\section{Conclusion, Implications for the pathogenesis of diabetes mellitus and possible treatment options}

The ability of central leptin to suppress hepatic glucose production in insulin sensitive rats supports the role of hypothalamic control of glucose homeostasis. Interestingly several studies (Brown and Goldstein 2008) showed that hepatic insulin resistance only affected glucose metabolism, while de-novo lipogenesis increased due to hyperinsulinemia. Our study shows that $\mathrm{MBH}$ leptin or insulin does not affect key enzymes involved in denovo lipogenesis, but $\mathrm{MBH}$ leptin in turn is able to increase hepatic insulin sensitivity to suppress hGP, supported by earlier studies (Pocai et al. 2005b) demonstrating improved insulin sensitivity through central leptin 
administration in a model of induced insulin resistance (caused by a brief period of high fat feeding).

While centrally administered leptin or insulin would be unfeasible in a clinical setup, earlier studies investigated intranasal application of insulin (Benedict et al. 2008, Born et al. 2002, Hallschmid et al. 2012) and showed clinical benefit by reducing calorie intake in men or increasing postprandial satiety in women without reducing overall calorie intake. Studies investigating intranasal leptin recently showed a significant reduction of appetite and weight in a rodent model (Schulz et al. 2012). Further clinical studies involving intranasal application of either insulin or leptin are therefore a promising option for additional treatment of obesity or $\mathrm{DM} 2$, as managing blood glucose levels today is still understood as the single most important, yet challenging (Ahola and Groop 2012) step in treatment of DM.

With regard to fatty acid metabolism and TCA cycle anaplerosis, we found implications for suppressed long chain fatty acid $\beta$-oxidation and favoring of carbohydrate and amino acid utilization in oxidative phosphorylation. As $\mathrm{MBH}$ insulin has been shown to suppress lipolysis in WAT (Scherer et al. 2011), $\mathrm{MBH}$ leptin is known to induce lipolysis in WAT (Buettner et al. 2008). While our glycerol tracer analysis support a decrease of systemic lipolysis through $\mathrm{MBH}$ insulin, no change could be seen for $\mathrm{MBH}$ leptin indicating that an increase in lipolysis in visceral WAT may be counter regulated through an increase in fatty acid and glycerol metabolism/utilization which leptin is known to induce (Park et al. 2006). Although systemic NEFA levels remained unchanged in both leptin and insulin $\mathrm{MBH}$ infused animals, FFA levels in the portal vein might be decreased or increased respectively, as elevated NEFA levels have been shown to increase gluconeogenesis and glycogenolysis in a hyperglycemic state (Kehlenbrink et al. 2012). Therefore a decrease of lipolysis by $\mathrm{MBH}$ insulin might in part be responsible for $\mathrm{MBH}$ insulin's ability to suppress hGP (Scherer et al. 2011).

Central leptin and insulin largely regulate WAT metabolism through the sympathetic nervous system. If central leptin and insulin only affected hepatic 
metabolism through this system, one would expect opposing effects on hepatic metabolism. Yet most changes seen in liver samples are similar in both treatment groups, suggestive of alternative signaling pathways, including but not limited to the parasympathetic nervous system (Li et al. 2011).

Nonetheless decrease in fatty acid $\beta$-oxidation without increase of systemic fatty acids or triglycerides raise the clinically relevant question if increased hypothalamic levels of either leptin or insulin abet the development of steatosis hepatis (Satapati et al. 2012, Sunny et al. 2011), although studies investigating chronic ICV leptin infusion found hepatic triglycerides to actually be decreased (Warne et al. 2011).

Our work demonstrates that both insulin and leptin alter hepatic energy metabolism. We find that insulin and leptin alter branched-chain amino acid (BCAA) levels in blood plasma. Earlier studies have suggested that increased BCAAs are associated with insulin resistance (Newgard et al. 2009, Newgard 2012, Shah et al. 2012) or might even serve as novel biomarkers to evaluate risk of DM (Lu et al. 2013a, McCormack et al. 2013). Elevated BCAAs could either be due to increased protein intake that is commonly seen in a western diet, or through metabolism of protein (Tai et al. 2010). Consistent with our observations of decreased plasma BCAAs is the notion that insulin is an anabolic hormone that suppresses proteolysis and lipolysis (Burns et al. 1979, Goldberg 1979); and although leptin is not understood to be an anabolic hormone, it is able to preserve lean body mass while reducing fat mass and therefore has anabolic properties (Halaas et al. 1995).

Our work therefore identifies numerous pathways affected by central leptin and insulin. Further studies are needed to examine the exact mechanisms leading to the observed changes in metabolite levels. 


\subsection{Limitations}

\section{Group size and the use of an animal model}

One limiting factor in our study was probably the small group size of 4 animals (3-4 for MBH aCSF) in the stable-isotope tracer group. Since metabolomics and pancreatic clamps are very expensive and time-consuming we were not able to perform additional metabolomic analysis to increase the group size. Furthermore, our repeated clamps in turn did clearly show the effect we anticipated, despite their relatively small group size.

An animal model often serves as a substitute for studies in humans, because of the feasibility and fewer genetic variables of inbred animals. In addition, animal care guidelines recommend the use of the smallest animals sufficient to conduct a study, which in our case resulted in a rat model. While we could have used mice instead, the recovery rate of rats after surgery and the accuracy of correctly placed MBH cannulae were markedly improved when using rats instead of mice.

The discrepancy in metabolic pathways between rats and humans might nonetheless affect the applicability of our study in humans. 


\section{Summary}

Background: While hepatic insulin resistance arises as one of the earliest causes of impaired glucose tolerance (IGT) and diabetes mellitus type 2 (DM2), the metabolic pathways involved are still poorly understood. In recent years the hypothalamus has been demonstrated to regulate whole body glucose and lipid metabolism and therefore DM2 and IGT. In an unbiased non-hypothesis driven approach our study aimed to further dissect the metabolic pathways affected by hypothalamic insulin and leptin signaling.

Methods: In order to investigate the role of leptin and insulin signaling in the hypothalamus, we infused leptin or insulin into the mediobasal Hypothalamus (MBH) of male Sprague-Dawley rats and measured glucose production, glucose uptake via tracer-dilution technique under euglycemic pancreatic clamp conditions. Western blots, enzyme linked assays and mass spectrometry, were used to simultaneously analyse multiple metabolic pathways.

Results: MBH leptin and insulin have similar effects on hepatic energy metabolism (figure 16). Targeted metabolomics analysis revealed (via measurement of acylcarnitines) that central insulin and leptin suppress long chain fatty acid $\beta$-oxidation in the liver and lead to increased levels of several TCA cycle intermediates (figure 16) as well as decreased branched-chain amino acids (BCAAs) in blood plasma.

Conclusion: The actions of leptin and insulin in the $\mathrm{MBH}$ increased gluconeogenic substrate breakdown in the liver through a decrease in fatty acid B-oxidation and an increase of oxidative phosphorylation of amino acid and glucose metabolites. Moreover, central leptin and insulin improved insulin sensitivity and the metabolic profile through reductions in plasma levels of branched chain $A A$, which are frequently increased in patients with $D M$. 


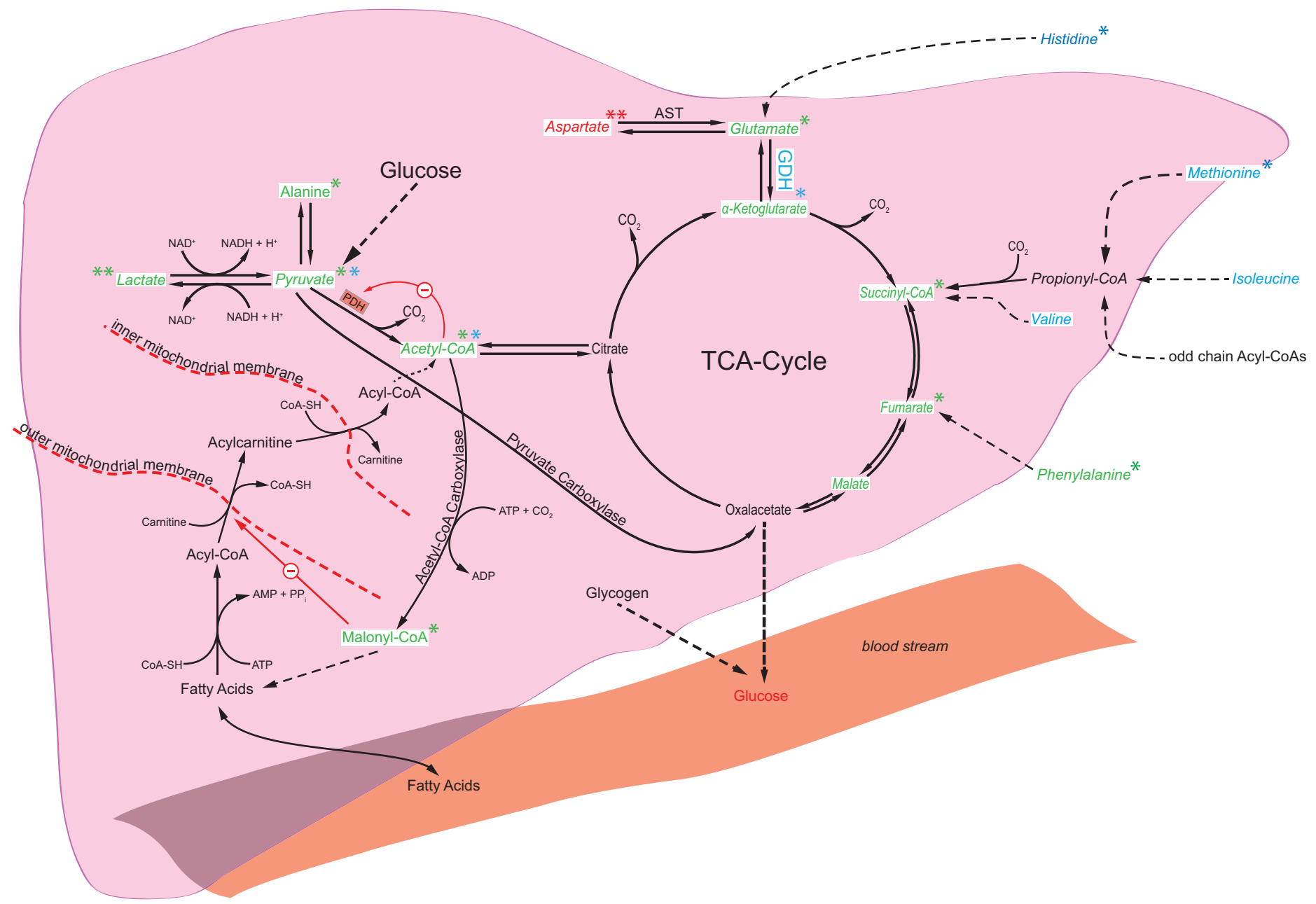

Figure 16: Illustration of selected metabolites and their role in shown metabolic pathways. $\left({ }^{*} P<\right.$ $0.05 \mathrm{MBH}$ aCSF vs. MBH Insulin and MBH Leptin; ${ }^{* *} \mathrm{P}<0.01$ aCSF vs. MBH Insulin and MBH Leptin, student's two-tailed unpaired t-Test, $n=4)$. Green shows an increase in metabolite levels in MBH leptin treated animals vs. MBH aCSF, Light blue formatted metablites are increased in $\mathrm{MBH}$ insulin treated animals vs. MBH aCSF. Red indicates a decrease of the metabolite in $\mathrm{MBH}$ leptin vs. vehicle. Malonyl-Coa increase implicated impaired CPT activity and therefore decreased oxidative phosphorylation of fatty acid derived acylcarnitines. The overall increase in TCA cycle metabolites, known as anaplerosis, indicated an increased flux through the TCA cycle. Mostly metabolites from glucose and gluconeogenic amino acids were increased, underscoring a proposed switch from fatty acid to glucose and amino acid utilization in treated animals. 


\section{References}

Abu-Elheiga L, Matzuk MM, Abo-Hashema KA, Wakil SJ (2001): Continuous fatty acid oxidation and reduced fat storage in mice lacking acetyl-CoA carboxylase 2. Science 291, 2613-2616

Ahola AJ, Groop PH (2012): Barriers to self-management of diabetes. Diabet Med $\underline{4}, 413-420$

Air EL, Benoit SC, Blake Smith KA, Clegg DJ, Woods SC (2002): Acute third ventricular administration of insulin decreases food intake in two paradigms. Pharmacol Biochem Behav 72, 423-429

Alves HN, da Silva AL, Olsson IA, Orden JM, Antunes LM (2010): Anesthesia with intraperitoneal propofol, medetomidine, and fentanyl in rats. J Am Assoc Lab Anim Sci 49, 454-459

Amiel SA, Sherwin RS, Simonson DC, Lauritano AA, Tamborlane WV (1986): Impaired insulin action in puberty. A contributing factor to poor glycemic control in adolescents with diabetes. N Engl J Med 315, 215-219

Baskin DG, Hahn TM, Schwartz MW (1999): Leptin sensitive neurons in the hypothalamus. Horm Metab Res 31, 345-350

Benedict C, Kern W, Schultes B, Born J, Hallschmid M (2008): Differential sensitivity of men and women to anorexigenic and memory-improving effects of intranasal insulin. J Clin Endocrinol Metab 93, 1339-1344

Berry JD, Dyer A, Cai X, Garside DB, Ning H, Thomas A, Greenland P, Van Horn L, Tracy RP, Lloyd-Jones DM (2012): Lifetime risks of cardiovascular disease. N Engl J Med 366, 321-329

Bhuiyan AK, Bartlett K, Sherratt HS, Agius L (1988): Effects of ciprofibrate and 2[5-(4-chlorophenyl)pentyl]oxirane-2-carboxylate (POCA) on the distribution of carnitine and CoA and their acyl-esters and on enzyme activities in rats. Relation between hepatic carnitine concentration and carnitine acetyltransferase activity. Biochem J 253, 337-343 
Born J, Lange T, Kern W, McGregor GP, Bickel U, Fehm HL (2002): Sniffing neuropeptides: a transnasal approach to the human brain. Nat Neurosci 5 , 514516

Brady PS, Ramsay RR, Brady LJ (1993): Regulation of the long-chain carnitine acyltransferases. FASEB J 7, 1039-1044

Brown MS, Goldstein JL (2008): Selective versus total insulin resistance: a pathogenic paradox. Cell Metab 7, 95-96

Bruning JC, Gautam D, Burks DJ, Gillette J, Schubert M, Orban PC, Klein R, Krone W, Muller-Wieland D, Kahn CR (2000): Role of Brain Insulin Receptor in Control of Body Weight and Reproduction. Science 289, 2122-2125

Buettner C, Pocai A, Muse ED, Etgen AM, Myers MG, Jr., Rossetti L (2006): Critical role of STAT3 in leptin's metabolic actions. Cell Metab $\underline{4}, 49-60$

Buettner C, Camacho RC (2008): Hypothalamic control of hepatic glucose production and its potential role in insulin resistance. Endocrinol Metab ClinNorth Am 37, 825-840

Buettner C, Muse ED, Cheng A, Chen L, Scherer T, Pocai A, Su K, Cheng B, Li X, Harvey-White J et al. (2008): Leptin controls adipose tissue lipogenesis via central, STAT3-independent mechanisms. Nat Med 14, 667-675

Burns TW, Terry BE, Langley PE, Robison GA (1979): Insulin inhibition of lipolysis of human adipocytes: the role of cyclic adenosine monophosphate. Diabetes 28, 957-961

Cahill GF, Jr. (2006): Fuel metabolism in starvation. Annu Rev Nutr 26, 1-22

Campfield LA, Smith FJ, Guisez Y, Devos R, Burn P (1995): Recombinant mouse OB protein: evidence for a peripheral signal linking adiposity and central neural networks. Science 269, 546-549

Carvalheira JB, Ribeiro EB, Araujo EP, Guimaraes RB, Telles MM, Torsoni M, Gontijo JA, Velloso LA, Saad MJ (2003): Selective impairment of insulin signalling in the hypothalamus of obese Zucker rats. Diabetologia $\underline{46}, 1629-1640$ 
Chavez M, Kaiyala K, Madden LJ, Schwartz MW, Woods SC (1995): Intraventricular insulin and the level of maintained body weight in rats. Behav Neurosci 109, 528-531

Cohen P, Zhao C, Cai X, Montez JM, Rohani SC, Feinstein P, Mombaerts P, Friedman JM (2001): Selective deletion of leptin receptor in neurons leads to obesity. J Clin Invest 108, 1113-1121

Danaei G, Finucane MM, Lu Y, Singh GM, Cowan MJ, Paciorek CJ, Lin JK, Farzadfar F, Khang YH, Stevens GA et al. (2011): National, regional, and global trends in fasting plasma glucose and diabetes prevalence since 1980: systematic analysis of health examination surveys and epidemiological studies with 370 countryyears and 2.7 million participants. Lancet $378,31-40$

de Boer IH, Sun W, Cleary PA, Lachin JM, Molitch ME, Steffes MW, Zinman B (2011): Intensive diabetes therapy and glomerular filtration rate in type 1 diabetes. N Engl J Med 365, 2366-2376

Doh KO, Kim YW, Park SY, Lee SK, Park JS, Kim JY (2005): Interrelation between long-chain fatty acid oxidation rate and carnitine palmitoyltransferase 1 activity with different isoforms in rat tissues. Life Sci 77, 435-443

Felig P, Marliss E, Cahill GF, Jr. (1969): Plasma amino acid levels and insulin secretion in obesity. N Engl J Med 281, 811-816

Felig P (1973): The glucose-alanine cycle. Metabolism 22, 179-207

Felig P (1974): Diabetic ketoacidosis. N Engl J Med 290, 1360-1363

Ferrara CT, Wang P, Neto EC, Stevens RD, Bain JR, Wenner BR, Ilkayeva OR, Keller MP, Blasiole DA, Kendziorski C et al. (2008): Genetic networks of liver metabolism revealed by integration of metabolic and transcriptional profiling. PLoS Genet 4, e1000034

Ginter E, Simko V (2012): Global prevalence and future of diabetes mellitus. Adv Exp Med Biol 771, 35-41 
Goldberg AL (1979): Influence of insulin and contractile activity on muscle size and protein balance. Diabetes 28 Suppl 1, 18-24

Goodman MN, McElaney MA, Ruderman NB (1981): Adaptation to prolonged starvation in the rat: curtailment of skeletal muscle proteolysis. Am J Physiol 241, E321-327

Gutierrez-Juarez R, Obici S, Rossetti L (2004): Melanocortin-independent effects of leptin on hepatic glucose fluxes. J Biol Chem 279, 49704-49715

Halaas JL, Gajiwala KS, Maffei M, Cohen SL, Chait BT, Rabinowitz D, Lallone RL, Burley SK, Friedman JM (1995): Weight-reducing effects of the plasma protein encoded by the obese gene. Science $269,543-546$

Hallschmid M, Higgs S, Thienel M, Ott V, Lehnert H (2012): Postprandial administration of intranasal insulin intensifies satiety and reduces intake of palatable snacks in women. Diabetes $\underline{61}, 782-789$

Hardie DG (2004): The AMP-activated protein kinase pathway--new players upstream and downstream. J Cell Sci 117, 5479-5487

Hawley SA, Davison M, Woods A, Davies SP, Beri RK, Carling D, Hardie DG (1996): Characterization of the AMP-activated protein kinase kinase from rat liver and identification of threonine 172 as the major site at which it phosphorylates AMP-activated protein kinase. J Biol Chem 271, 27879-27887

Heiling VJ, Campbell PJ, Gottesman IS, Tsalikian E, Beaufrere B, Gerich JE, Haymond MW (1993): Differential effects of hyperglycemia and hyperinsulinemia on leucine rate of appearance in normal humans. J Clin Endocrinol Metab 76, 203-206

Holman RR, Paul SK, Bethel MA, Matthews DR, Neil HA (2008): 10-year follow-up of intensive glucose control in type 2 diabetes. N Engl J Med 359, 1577-1589

Jung CH, Kim MS (2013): Molecular mechanisms of central leptin resistance in obesity. Arch Pharm Res 36, 201-207 
Kehlenbrink S, Koppaka S, Martin M, Relwani R, Cui MH, Hwang JH, Li Y, Basu R, Hawkins M, Kishore P (2012): Elevated NEFA levels impair glucose effectiveness by increasing net hepatic glycogenolysis. Diabetologia 55, 3021-3028

Koch C, Augustine RA, Steger J, Ganjam GK, Benzler J, Pracht C, Lowe C, Schwartz MW, Shepherd PR, Anderson GM et al. (2010): Leptin rapidly improves glucose homeostasis in obese mice by increasing hypothalamic insulin sensitivity. J Neurosci 30, 16180-16187

Koubaa M, Cocuron JC, Thomasset B, Alonso AP (2013): Highlighting the tricarboxylic acid cycle: liquid and gas chromatography-mass spectrometry analyses of (13)C-labeled organic acids. Anal Biochem 436(2), 151-159

Koves TR, Ussher JR, Noland RC, Slentz D, Mosedale M, Ilkayeva O, Bain J, Stevens R, Dyck JR, Newgard CB et al. (2008): Mitochondrial overload and incomplete fatty acid oxidation contribute to skeletal muscle insulin resistance. Cell Metab $\underline{7}$, 45-56

Krebs M, Krssak M, Bernroider E, Anderwald C, Brehm A, Meyerspeer M, Nowotny P, Roth E, Waldhausl W, Roden M (2002): Mechanism of amino acidinduced skeletal muscle insulin resistance in humans. Diabetes $\underline{51}, 599-605$

Lam CK, Chari M, Rutter GA, Lam TK (2010): Hypothalamic nutrient sensing activates a forebrain-hindbrain neuronal circuit to regulate glucose production in vivo. Diabetes $\underline{60,107-113}$

Lam TK, Pocai A, Gutierrez-Juarez R, Obici S, Bryan J, Aguilar-Bryan L, Schwartz GJ, Rossetti L (2005): Hypothalamic sensing of circulating fatty acids is required for glucose homeostasis. NatMed 11, 320-327

Li X, Wu X, Camacho R, Schwartz GJ, LeRoith D (2011): Intracerebroventricular leptin infusion improves glucose homeostasis in lean type 2 diabetic MKR mice via hepatic vagal and non-vagal mechanisms. PLoS One 6, e17058

Lindtner C, Scherer T, Zielinski E, Filatova N, Fasshauer M, Tonks NK, Puchowicz M, Buettner C (2013): Binge drinking induces whole-body insulin resistance by impairing hypothalamic insulin action. Sci Transl Med 5, 170ra114 
Liu L, Karkanias GB, Morales JC, Hawkins M, Barzilai N, Wang J, Rossetti L (1998): Intracerebroventricular leptin regulates hepatic but not peripheral glucose fluxes. J Biol Chem 273, 31160-31167

Lu J, Xie G, Jia W (2013a): Insulin resistance and the metabolism of branchedchain amino acids. Front Med 7, 53-59

Lu J, Xie G, Jia W (2013b): Metabolomics in human type 2 diabetes research. Front Med 7, 4-13

Mabrouk GM, Helmy IM, Thampy KG, Wakil SJ (1990): Acute hormonal control of acetyl-CoA carboxylase. The roles of insulin, glucagon, and epinephrine. J Biol Chem 265, 6330-6338

Mauer M, Zinman B, Gardiner R, Suissa S, Sinaiko A, Strand T, Drummond K, Donnelly S, Goodyer P, Gubler MC et al. (2009): Renal and retinal effects of enalapril and losartan in type 1 diabetes. N Engl J Med 361, 40-51

McCormack SE, Shaham O, McCarthy MA, Deik AA, Wang TJ, Gerszten RE, Clish CB, Mootha VK, Grinspoon SK, Fleischman A (2013): Circulating branched-chain amino acid concentrations are associated with obesity and future insulin resistance in children and adolescents. Pediatr Obes $\underline{8}, 52-61$

Michaliszyn SF, Sjaarda LA, Mihalik SJ, Lee S, Bacha F, Chace DH, De Jesus VR, Vockley J, Arslanian SA (2012): Metabolomic profiling of amino acids and betacell function relative to insulin sensitivity in youth. J Clin Endocrinol Metab 97, E2119-2124

Minokoshi Y, Kim YB, Peroni OD, Fryer LG, Muller C, Carling D, Kahn BB (2002): Leptin stimulates fatty-acid oxidation by activating AMP-activated protein kinase. Nature $\underline{415}, 339-343$

Monetti M, Levin MC, Watt MJ, Sajan MP, Marmor S, Hubbard BK, Stevens RD, Bain JR, Newgard CB, Farese RV, Sr. et al. (2007): Dissociation of hepatic steatosis and insulin resistance in mice overexpressing DGAT in the liver. Cell Metab 6, 69-78

Montague CT, Farooqi IS, Whitehead JP, Soos MA, Rau H, Wareham NJ, Sewter CP, Digby JE, Mohammed SN, Hurst JA et al. (1997): Congenital leptin deficiency is associated with severe early-onset obesity in humans. Nature 387, 903-908 
Newgard CB, An J, Bain JR, Muehlbauer MJ, Stevens RD, Lien LF, Haqq AM, Shah SH, Arlotto M, Slentz CA et al. (2009): A branched-chain amino acid-related metabolic signature that differentiates obese and lean humans and contributes to insulin resistance. Cell Metab 9, 311-326

Newgard CB (2012): Interplay between lipids and branched-chain amino acids in development of insulin resistance. Cell Metab $\underline{15}$, 606-614

Obici S, Zhang BB, Karkanias G, Rossetti L (2002): Hypothalamic insulin signaling is required for inhibition of glucose production. NatMed $8,1376-1382$

Ono H, Pocai A, Wang Y, Sakoda H, Asano T, Backer JM, Schwartz GJ, Rossetti L (2008): Activation of hypothalamic S6 kinase mediates diet-induced hepatic insulin resistance in rats. J ClinInvest 118, 2959-2968

Orci L, Cook WS, Ravazzola M, Wang MY, Park BH, Montesano R, Unger RH (2004): Rapid transformation of white adipocytes into fat-oxidizing machines. Proc Natl Acad Sci U S A 101, 2058-2063

Owen OE, Kalhan SC, Hanson RW (2002): The key role of anaplerosis and cataplerosis for citric acid cycle function. J Biol Chem 277, 30409-30412

Pansky B, Hatfield JS (1978): Cerebral localization of insulin by immunofluorescence. Am J Anat 153, 459-467

Park BH, Wang MY, Lee Y, Yu X, Ravazzola M, Orci L, Unger RH (2006): Combined leptin actions on adipose tissue and hypothalamus are required to deplete adipocyte fat in lean rats: implications for obesity treatment. J Biol Chem 281, 40283-40291

Patel A, MacMahon S, Chalmers J, Neal B, Billot L, Woodward M, Marre M, Cooper M, Glasziou P, Grobbee D et al. (2008): Intensive blood glucose control and vascular outcomes in patients with type 2 diabetes. N Engl J Med 358, 2560-2572

Paxinos G, Watson C (1998): The Rat Brain in Stereotaxic Coordinates 4th edn. Academic Press, San Diego 1998 
Pelleymounter MA, Cullen MJ, Baker MB, Hecht R, Winters D, Boone T, Collins F (1995): Effects of the obese gene product on body weight regulation in ob/ob mice. Science 269, 540-543

Pinhas-Hamiel 0, Zeitler P (2005): The global spread of type 2 diabetes mellitus in children and adolescents. J Pediatr 146, 693-700

Pocai A, Lam TK, Gutierrez-Juarez R, Obici S, Schwartz GJ, Bryan J, Aguilar-Bryan L, Rossetti L (2005a): Hypothalamic K(ATP) channels control hepatic glucose production. Nature 434, 1026-1031

Pocai A, Morgan K, Buettner C, Gutierrez-Juarez R, Obici S, Rossetti L (2005b): Central leptin acutely reverses diet-induced hepatic insulin resistance. Diabetes $\underline{54}, 3182-3189$

Pocai A, Obici S, Schwartz GJ, Rossetti L (2005c): A brain-liver circuit regulates glucose homeostasis. Cell Metab $1,53-61$

Pocai A, Lam TK, Obici S, Gutierrez-Juarez R, Muse ED, Arduini A, Rossetti L (2006): Restoration of hypothalamic lipid sensing normalizes energy and glucose homeostasis in overfed rats. J Clin Invest 116, 1081-1091

Ramsay RR, Gandour RD, van der Leij FR (2001): Molecular enzymology of carnitine transfer and transport. Biochim Biophys Acta 1546, 21-43

Rathmann W, Strassburger K, Heier M, Holle R, Thorand B, Giani G, Meisinger C (2009): Incidence of Type 2 diabetes in the elderly German population and the effect of clinical and lifestyle risk factors: KORA S4/F4 cohort study. Diabet Med 26, 1212-1219

Roman EA, Cesquini M, Stoppa GR, Carvalheira JB, Torsoni MA, Velloso LA (2005): Activation of AMPK in rat hypothalamus participates in cold-induced resistance to nutrient-dependent anorexigenic signals. J Physiol 568, 993-1001

Satapati S, Sunny NE, Kucejova B, Fu X, He TT, Mendez-Lucas A, Shelton JM, Perales JC, Browning JD, Burgess SC (2012): Elevated TCA cycle function in the pathology of diet-induced hepatic insulin resistance and fatty liver. J Lipid Res $\underline{53}, 1080-1092$ 
Scherer T, O'Hare J, Diggs-Andrews K, Schweiger M, Cheng B, Lindtner C, Zielinski E, Vempati P, Su K, Dighe S et al. (2011): Brain insulin controls adipose tissue lipolysis and lipogenesis. Cell Metab 13, 183-194

Scherer T, Lindtner C, Zielinski E, O'Hare J, Filatova N, Buettner C (2012): Short term voluntary overfeeding disrupts brain insulin control of adipose tissue lipolysis. J Biol Chem 287, 33061-33069

Schulz C, Paulus K, Johren 0, Lehnert H (2012): Intranasal leptin reduces appetite and induces weight loss in rats with diet-induced obesity (DIO). Endocrinology 153, 143-153

Schutz Y (2011): Protein turnover, ureagenesis and gluconeogenesis. Int J Vitam Nutr Res 81, 101-107

Schwartz MW, Woods SC, Porte D, Jr., Seeley RJ, Baskin DG (2000): Central nervous system control of food intake. Nature 404, 661-671

Schwartz MW, Porte D, Jr. (2005): Diabetes, obesity, and the brain. Science 307, 375-379

Shah SH, Crosslin DR, Haynes CS, Nelson S, Turer CB, Stevens RD, Muehlbauer MJ, Wenner BR, Bain JR, Laferrere B et al. (2012): Branched-chain amino acid levels are associated with improvement in insulin resistance with weight loss. Diabetologia 55, 321-330

Shaw RJ, Kosmatka M, Bardeesy N, Hurley RL, Witters LA, DePinho RA, Cantley LC (2004): The tumor suppressor LKB1 kinase directly activates AMP-activated kinase and regulates apoptosis in response to energy stress. Proc Natl Acad Sci U S A 101, 3329-3335

Sunny NE, Parks EJ, Browning JD, Burgess SC (2011): Excessive hepatic mitochondrial TCA cycle and gluconeogenesis in humans with nonalcoholic fatty liver disease. Cell Metab 14, 804-810

Tai ES, Tan ML, Stevens RD, Low YL, Muehlbauer MJ, Goh DL, Ilkayeva OR, Wenner BR, Bain JR, Lee JJ et al. (2010): Insulin resistance is associated with a metabolic profile of altered protein metabolism in Chinese and Asian-Indian men. Diabetologia 53, 757-767 
Tesfaye S, Chaturvedi N, Eaton SE, Ward JD, Manes C, Ionescu-Tirgoviste C, Witte DR, Fuller JH (2005): Vascular risk factors and diabetic neuropathy. N Engl J Med 352, 341-350

Toda C, Shiuchi T, Kageyama H, Okamoto S, Coutinho EA, Sato T, OkamatsuOgura Y, Yokota S, Takagi K, Tang L et al. (2013): Extracellular Signal-Regulated Kinase in the Ventromedial Hypothalamus Mediates Leptin-Induced Glucose Uptake in Red-Type Skeletal Muscle. (Diabetes, published ahead of print March 25,2013 )

Turer AT, Stevens RD, Bain JR, Muehlbauer MJ, van der Westhuizen J, Mathew JP, Schwinn DA, Glower DD, Newgard CB, Podgoreanu MV (2009): Metabolomic profiling reveals distinct patterns of myocardial substrate use in humans with coronary artery disease or left ventricular dysfunction during surgical ischemia/reperfusion. Circulation 119, 1736-1746

Wang MY, Chen L, Clark GO, Lee Y, Stevens RD, Ilkayeva OR, Wenner BR, Bain JR, Charron MJ, Newgard CB et al. (2010): Leptin therapy in insulin-deficient type I diabetes. Proc Natl Acad Sci U S A 107, 4813-4819

Warne JP, Alemi F, Reed AS, Varonin JM, Chan H, Piper ML, Mullin ME, Myers MG, Jr., Corvera CU, Xu AW (2011): Impairment of central leptin-mediated PI3K signaling manifested as hepatic steatosis independent of hyperphagia and obesity. Cell Metab 14, 791-803

Weigle DS, Bukowski TR, Foster DC, Holderman S, Kramer JM, Lasser G, LoftonDay CE, Prunkard DE, Raymond C, Kuijper JL (1995): Recombinant ob protein reduces feeding and body weight in the ob/ob mouse. J Clin Invest 96, 20652070

Woods SC, Lotter EC, McKay LD, Porte D, Jr. (1979): Chronic intracerebroventricular infusion of insulin reduces food intake and body weight of baboons. Nature 282, 503-505

Wu Q, Boyle MP, Palmiter RD (2009): Loss of GABAergic signaling by AgRP neurons to the parabrachial nucleus leads to starvation. Cell 137, 1225-1234

Zhang W, Ambati S, Della-Fera MA, Choi YH, Baile CA, Andacht TM (2010): Leptin Modulated Changes in Adipose Tissue Protein Expression in ob/ob Mice. Obesity (Silver Spring) 19, 255-261 


\section{Acknowledgments}

First of all I would like to thank my doctoral adviser Prof. Dr. Dirk Raddatz and principal investigator Dr. Christoph Buettner, MD, PhD for their continuous support, enabling me to conduct my thesis at the Mount Sinai Hospital in New York. Thanks to my former co-workers in the lab, especially Dr. Thomas Scherer for supporting and teaching me in theory and methods at any given time, Elizabeth Zieliński and James O'Hare for excellent collaboration during the experiments and Dr. Claudia Lindtner, MD as well as Prashant Vempati for invaluable exchange of ideas regarding my project.

Special thanks go to Olga R. Ilkayeva, PhD Robert D. Stevens, PhD and James R. Bain, PhD from Sarah W. Stedman Nutrition \& Metabolism Center for the outstanding metabolomics data.

Further on I want to thank for financial support from the Boehringer Ingelheim Fonds, as I would not have been able to fulfill my thesis without it. 